Article

\title{
Impact of Open Innovation Communities on Enterprise Innovation Performance: A System Dynamics Perspective
}

\author{
Bing $\mathrm{Wu} * \mathbb{\infty}$ and Chunyu Gong \\ School of Economics and Management, Tongji University, Shanghai 200092, China \\ * Correspondence: wubingsem@tongji.edu.cn
}

Received: 16 July 2019; Accepted: 30 August 2019; Published: 3 September 2019

\begin{abstract}
Open innovation communities (OICs) can help enterprises make full use of external knowledge resources from users, but problems such as low user participation and low conversion rate of creative ideas impact the efficiency of OICs. Most studies on this topic employ qualitative or empirical methods from a static perspective, but ignore the effect of interaction between enterprises and users as well as the cumulative effect of time. A discussion on the dynamic evolution process of open innovation is lacking. Based on a review of the literature on OICs, innovation performance, and system dynamics, this study proposes a conceptual model of innovation performance impact, which comprises the knowledge management, governance mechanism, and user behavior subsystems. Xiaomi's OIC in China was selected as the research object, and relevant data were collected through a web spider. According to the system dynamics modeling method, a causal relationship analysis was carried out on the three aforementioned interrelated subsystems. Then, a stock flow chart with 32 variables was constructed to determine the initial values and calculation equations for each variable. Finally, the model was constructed and verified using Vensim PLE software. The simulation results were as follows. (1) The number of product releases in the Xiaomi OIC was positively correlated with the number of posts, comments, and views. Compared with user interaction behavior (i.e., commenting and viewing), the impact of user innovation behavior (i.e., posting) on enterprise innovation performance (i.e., number of patents) is clearer. Specifically, regarding interaction behavior, the impact of the users' commenting behavior on innovation performance (i.e., number of product releases) was relatively clearer than that of their viewing behavior. (2) Governance mechanism (i.e., R\&D investment and management expense), which comprises technical and organizational mechanisms, positively affected the innovation performance of enterprises. Compared with the organizational mechanism (i.e., management expense), the impact of the technical mechanism (i.e., R\&D investment) on the innovation performance was clearer. (3) Governance mechanism helped to increase the number of users in the OIC, and, in turn, affected the user innovation and interaction behavior. (4) The technical mechanism positively affected knowledge application capability, which, in turn, had a positive impact on the innovation performance of enterprises. Based on these findings, management strategies are proposed for the establishment and development of OICs.
\end{abstract}

Keywords: open innovation community; innovation performance; system dynamics; knowledge management; governance mechanism

\section{Introduction}

With the advent of the knowledge economy, enterprises have formed various types of open innovation communities (OICs) to swiftly acquire knowledge resources from external users. These OICs help companies understand the market requirements, access external market information, 
collect external knowledge resources, and obtain feedback from users. In OICs, users actively share knowledge resources and create value, which is crucial for improving the companies' innovation performance. Regarding enterprise innovation, some creative ideas by OIC users have high innovation value, matching the companies' open innovation strategy. Consequently, user innovation and interaction behavior in an OIC generates a wealth of knowledge resources [1-3].

In recent years, OICs across the world have been developing rapidly, but many problems still persist. For example, although a large number of users share creative ideas every day, there are very few ideas that can actually lead to the creation of innovative products or services.

Enterprise development should rely not only on internal knowledge resources, but also on external knowledge resources. However, there are few studies investigating the impact of OICs on enterprise innovation performance. Moreover, most of them employ qualitative or empirical methods from a static perspective, ignoring the effect of interaction between enterprises and users and the cumulative effect of time. The dynamic evolution process of innovation and time lag of innovation performance have rarely been examined. Therefore, this study aimed to analyze the system dynamics on the impact of OICs on the innovation performance of enterprises. Specifically, the Xiaomi OIC, a successful example of an OIC in China, was used as the research object. In theory, system dynamics was introduced to enrich and expand the theoretical knowledge on OICs. In practice, the research results will help us understand the impact mechanism of OICs on innovation performance, and determine measures and countermeasures to optimize OIC management. Thus, theoretical and practical guidance is provided for the construction and development of OICs.

The rest of this paper is organized as follows. Section 2 reviews the literature, which offers a short overview of OICs, innovation performance, and system dynamics. Section 3 presents the conceptual model of innovation performance impact, which includes knowledge management, governance mechanism, and user behavior. This is followed by a discussion in Section 4 on the research design and methodology. Section 5 establishes and simulates a system dynamics model and describes the most relevant findings obtained. Finally, Section 6 summarizes the contributions of this study and discusses the research problems to be investigated in the future.

\section{Literature Review}

For a comprehensive understanding of our research topic, we conducted a literature review. The first two sections below summarize the OIC and innovation performance literature to understand how the use of system dynamics in this domain is justified. The following section introduces system dynamics to illustrate its operation mechanism.

\subsection{Open Innovation Community (OIC)}

With the advent of the concept of knowledge sharing and social economy, the role of users has changed over time. Users are no longer only passive recipients of products; they are more willing to actively express their own needs, participate in enterprises' innovation process, and share their ideas with others [4]. In this context, companies can use OICs to evaluate ideas posted by users, and through collective intelligence, choose the best of those ideas [5]. The essence of an OIC lies in utilizing all possibilities offered by internal and external users to create value for enterprises. In recent years, the number of OICs has grown exponentially [6]. Many multinational companies such as Haier, IBM, Dell, and Starbucks have begun building OICs to get external users to participate in the enterprise's innovation activities and internal product development.

From the perspective of users, OICs bring together users with similar interests or goals. Specifically, an OIC is composed of a large number of individuals who participate voluntarily and interact with each other to achieve a common goal [5]. From the perspective of the network platform, an OIC lets enterprises organize users who wish to interact on a common topic. OICs have a certain marketing feature: they are designed to attract customers to engage in interactive discussions and improve product awareness of existing and potential customers [7]. From the perspective of 
network organization, OICs are composed of individuals outside the organization, but with consensus on the organization. The core idea of OICs is to allow users to participate in the internal product development of the enterprise to boost product improvement and innovation [8]. As such, OICs have attracted widespread attention. The literature mainly considers three aspects in this context: technology application, knowledge management, and user management.

Regarding technology application, the development of information technology can enable enterprises to use emerging technology tools, which helps them integrate external innovation with internal innovation [9]. For example, text analysis is employed in the research on OICs, and, by summarizing different types of ideas, it helps corporate decision makers identify the most innovative ideas [10]. Accordingly, advances in information technology have made companies increasingly dependent on open innovation [11].

In terms of knowledge management, studies focus on the effective implementation of knowledge management in enterprises to transform the knowledge resources of external users into internal knowledge resources for the enterprise. For example, Santoro et al. empirically studied the relationship between open innovation, knowledge management, and innovation capabilities through structural equation modeling to show that knowledge management systems promote openness through the development of internal knowledge management capabilities [12]. The creation of collaborative systems and the internal and external knowledge resources increase the companies' ability to innovate.

With regard to user management, the literature focuses on the impact of user behavior on the open innovation process of enterprises. For example, Martínez-Torres analyzed the behavior of community members from the perspective of social network analysis, concluding that collective intelligence can help companies identify real innovators, those who have the potential to publish high-value and feasible ideas [5]. Moreover, Martínez-Torres et al. categorized creative ideas that users liked by themes, and compared those ideas to determine whether the ideas implemented by the enterprise met the user preferences [10].

\subsection{Influencing Factors of Innovation Performance}

Innovation performance refers to the enterprise's realization of economic, technological, and innovation goals through technological advancement, efficient business management methods, and high research and development (R\&D) capabilities. There are many indicators to measure innovation performance. For example, Zhou and Qi considered the performance of enterprises' product innovation and process innovation, and proposed a comprehensive measurement index comprising five aspects of innovation performances: number of new products, technical content, development success rate, market response, and production equipment using first-class advanced technology [13]. It is difficult to determine a uniform metric for innovation performance and to quantify it; thus, most studies have used the number of patents to assess innovation performance [14]. This is because, apart from patents signifying the innovation and novelty of knowledge, patent information is also easy to compare and collect.

There are many studies on the influencing factors of innovation performance that have built new models or extended the scope of existing models. Gold et al. proposed the impact model of enterprise innovation performance from the perspective of organizational competence [15]. According to this model, knowledge management ability and process capability can effectively improve the efficiency and competitiveness of enterprises. Knowledge management ability includes the technology, organizational structure, and organizational culture of the enterprise; process capability includes knowledge acquisition, transformation, application, and protection. Chen and Fong expanded this model by adding governance mechanisms [16]. In the process of open innovation, the innovation and interaction behavior of OIC users provides important external knowledge resources, which can affect the allocation of knowledge resources within the enterprise. Therefore, Julison et al. argued that the factors affecting innovation performance can be divided into three categories: drivers, internal factors, and external factors [17]. 
Research shows that enterprise-oriented social networking and organizational learning capabilities impact innovation performance. In the context of open innovation, there is often a delay in corporate innovation performance, because external knowledge resources are not immediately transformed into corporate innovation performance [18]. Increasing R\&D investment contributes to innovation performance. For example, Wang et al. considered R\&D investment as the main factor affecting innovation performance, taking into account auxiliary variables such as total assets, asset liability ratio, operating income, and establishment time, and established a panel measurement model [19]. They then used STATA software to analyze the specific impact of the R\&D investment on innovation performance.

In the field of science and technology innovation management, existing studies have mostly used qualitative or empirical analysis methods, ignoring the cumulative effect of time and the two-way effect of causality in OICs. Therefore, research on the dynamic influence mechanism of enterprise innovation performance is important, an issue that can be solved by the application of system dynamics.

\subsection{System Dynamics}

System dynamics takes into account the whole situation. It combines qualitative research and quantitative analysis to simulate the system influence mechanism and operation mode. System dynamics is effective for studying complex system characteristics and time-varying dynamic user behavior [20]. Moreover, system dynamics often uses graphical representations to investigate the feedback loop structure of the system. There are two common graphical representations: causal graphs and stock flow graphs.

The causal graph including variables and feedbacks is used in the initial stages of establishing a system dynamics model. Feedback refers to the relationship between the input and output of the same unit in the system. This can be divided into positive feedback and negative feedback, which is indicated by arrows with a positive or negative sign, depending on the context. Several feedbacks form a closed loop, whose sign (positive or negative) depends on the total number of negative feedbacks in the loop. When the number of negative feedbacks is even, the polarity of the feedback loop is positive. When the number of negative feedbacks is odd, the polarity of the loop is negative. Different polarities of feedback loops have different effects on system variables. Generally, positive polarity implies that the cumulative effect of the loop can produce an enhanced effect with increasing time, and, accordingly, the value of the variables increases. In the case of negative polarity, the cumulative effect of the loop is negative, and accordingly, the value of the variables decreases. As the system cannot expand indefinitely, the negative feedback loop helps sustain the system and ensures stability. As the causal graph is based on a qualitative description of the variables, it cannot reflect the quantitative connections and differences among variables.

Stock flow graphs can clearly reflect the dynamic feedback and cumulative effect of time of the system. With a quantitative description of variables, these graphs can distinguish between five types of variables: level variables, rate variables, auxiliary variables, constant variables, and exogenous variables. The level variable, also known as the accumulation variable, determines the behavior of the whole system. The value of the rate variable equals that of the level variable in unit time, that is, the speed of the level variable input or output. Thus, a change in the rate variable influences the value of the level variable. The auxiliary variable with independent values at unit time is calculated based on the values of other variables in the system. The exogenous variable affects other variables in the system without itself being affected by endogenous variables within the system.

Presently, system dynamics is widely used in almost all fields of human society and natural sciences, which can be summarized into three aspects: prediction [21-24], policy management $[25,26]$, and optimization and control [27-29].

Research on various information system fields has been increasing, but scholars have found that most of the literature is based on a static perspective of single causality, and there is little discussion on the interaction between dynamic evolution and various influencing factors. System dynamics can solve these problems, as a result, the system dynamics literature in the field of information systems has been enriched. 
$\mathrm{Xu}$ and Jiang explored the factors affecting knowledge management for state-owned commercial banks in financial services innovation through system dynamics [30]. In terms of e-commerce, An et al. analyzed the return policy in an e-commerce environment based on system dynamics [31], and Fang et al. used system dynamics to study the relationship between e-commerce investment and firm performance [32]. Wu et al. used system dynamics to simulate the recommendation of personalized information by analyzing the relationships between personal intention, community influence, user preference, resource complexity, and label selection algorithm in a label-based recommendation system [33]. The process reveals the mechanism and system characteristics of information recommendation and provides research ideas on the dynamic evolution process of personalized information recommendation.

In this study, the system dynamics was used to provide managers with management suggestions on the establishment and development of OICs.

\section{A Conceptual Model of Enterprise Innovation Performance}

We based our model on the impact model of innovation performance [16]. Taking into account the impact of user behavior in OICs on enterprise innovation performance and integrating user innovation behavior and interaction behaviors, a conceptual model of innovation performance impact was constructed, as shown in Figure 1. In the knowledge management module, the knowledge management capability will promote the ability of the enterprises to identify, acquire, transform, and apply knowledge resources, and thus improve their innovation performance [34]. In the community user behavior module, user innovation behavior will promote the generation of knowledge resources, and user interaction behavior can help the enterprise effectively select high-quality knowledge resources through collective knowledge. With a high quality of knowledge management capabilities, enterprises can transform the knowledge resources of external users to improve their innovation performance [35]. Enhanced innovation performance attracts more users to the OIC, which has a positive impact on user innovation and interaction behaviors. An efficient governance mechanism is conducive to improving knowledge management capabilities, which, in turn, has a positive impact on innovation performance, thereby helping companies gain more innovative revenue, and accelerate their development [36]. Therefore, more resources should be invested in a governance mechanism for enterprises, which covers organizational and technical mechanisms.

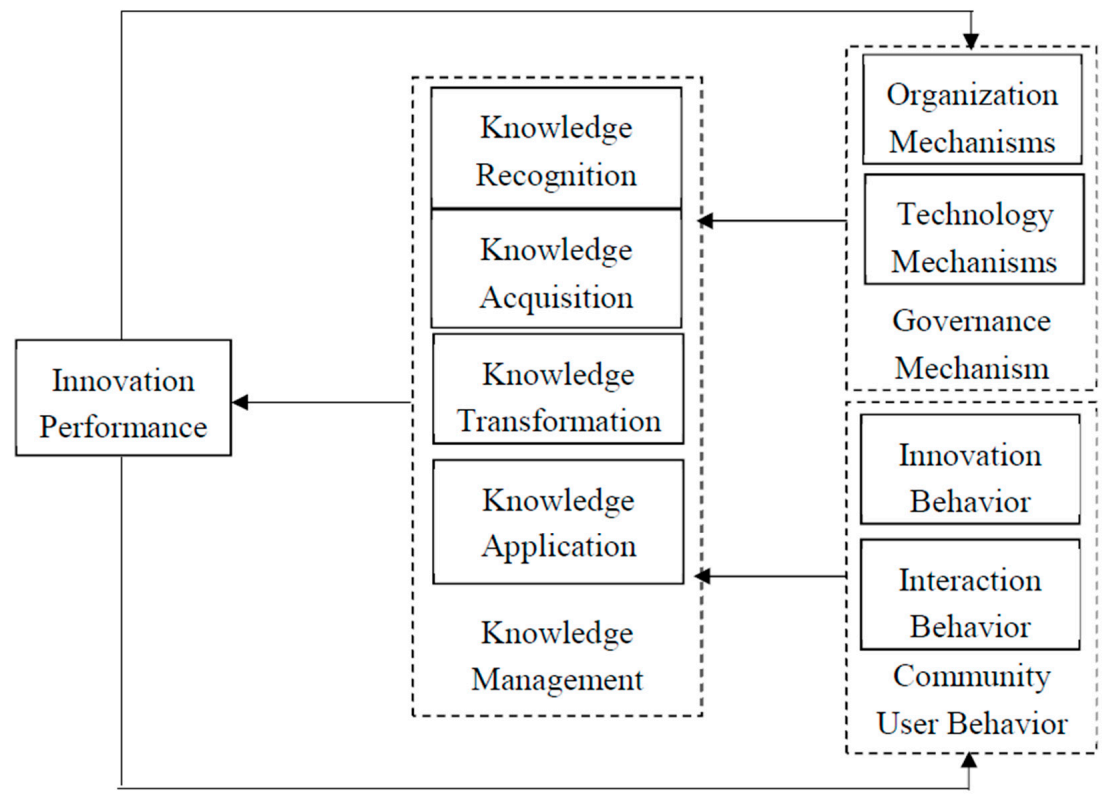

Figure 1. Conceptual model of the impact of open innovation communities (OICs) on enterprise innovation performance. 


\subsection{Knowledge Management Module}

The knowledge management process mainly includes identification, collection, acquisition, transfer, diffusion, transformation, sharing, absorption, integration, generation, creation, and application of knowledge [37]. In this study, considering the characteristics of OICs, the knowledge management process was divided into the following four dimensions: knowledge recognition, knowledge acquisition, knowledge transformation, and knowledge application. The companies' knowledge management capabilities help them transform innovation into real productivity and gain long-term competitive advantage.

\subsubsection{Knowledge Recognition}

Knowledge recognition refers to the enterprise's perception of stimulus from the external environment including knowledge from external users or competitive markets. Based on internal resource allocation, those resources that are valuable for the enterprise are selected from the numerous available resources. Knowledge recognition capabilities contribute by helping the enterprise make detailed observations of changes in the external environment, so that the enterprise is capable of making decisions according to user needs, thus capturing market opportunities [38]. The stronger the knowledge recognition capability, the faster the enterprise can mine external knowledge and discover hidden opportunities, which will help them quickly perceive changes in market trends and make corresponding adjustments and countermeasures in their operations.

\subsubsection{Knowledge Acquisition}

Through knowledge acquisition, enterprises absorb external knowledge and integrate it with internal knowledge, so that its knowledge capital can increase. Knowledge acquisition capabilities also help companies respond to changes in competitive markets and make strategic adjustments quickly [39]. The stronger the knowledge acquisition capability, the more easily enterprises can integrate external and internal knowledge resources. Thus, the efficiency of the transformation process of external into internal knowledge resources is improved [40].

\subsubsection{Knowledge Transformation}

Knowledge transformation can maximize the value of internal knowledge resources, and is reflected in the processes of knowledge processing, sharing, integrating, coordinating, and transferring. By knowledge transformation, tacit knowledge is transformed into explicit knowledge. Through the integration of explicit knowledge resources, enterprises can create new knowledge resources for themselves such as new technologies and products to achieve technological innovation and production process innovation [41]. The stronger the knowledge transformation capabilities, the more the knowledge resources are available for R\&D and innovation, which improves the ability of enterprises to adapt to competitive changes and market trends [42,43].

\subsubsection{Knowledge Application}

Knowledge application is the process whereby enterprises apply internal innovative knowledge to their production and management practices under the premises of knowledge recognition, knowledge acquisition, and knowledge transformation, which helps them launch new products or services. Knowledge application transforms knowledge into real productivity and helps improve technological and innovation capabilities of enterprises in the long run [44]. The stronger the knowledge application ability, the higher the efficiency of the knowledge value realization process, which helps enterprises bring in high revenues in competitive markets with unique innovation, thereby enhancing their innovation performance. 


\subsection{Governance Mechanism Module}

Organizational mechanisms are composed of technical and management mechanisms. Organizational and technical mechanisms provide support and the strategic guidance for the implementation of knowledge management from the perspectives of organization and technology, respectively.

\subsubsection{Organizational Mechanism}

There are two types of organizational mechanisms: formal organizational mechanisms and informal organizational mechanisms [16]. The formal organizational mechanism is directly affected by business management interventions such as management systems, compensation incentive systems, expense reimbursement processes, and divisions and tasks. The informal organizational mechanism reflects the intangible mechanisms of the management style, value system, and organizational culture. The informal mechanism is reflected in management's subjective awareness of the need to enhance the dynamic capabilities of the enterprise's knowledge management. A well-structured organization helps companies manage important and irreplaceable knowledge resources. The informal organizational mechanism can be embedded in organizational management and promotes the continuous updating of knowledge resources in product innovation [45].

The organizational mechanism includes a set of organizational management elements such as management inputs, incentives, and employee training. Due to the competitive external environment and the fast-changing nature of technology, employee training can help them learn about cutting-edge technology and take on more challenging and innovative work. Empirical studies show that an efficient organizational mechanism helps improve work efficiency, and has a positive impact on innovation performance [46].

\subsubsection{Technical Mechanisms}

Technical mechanisms include both technical capabilities and technical management capabilities. From the perspective of a resource-based view, technical capability enables enterprises to carry out technological innovation, process innovation, and product innovation including tangible resources such as R\&D equipment and R\&D investment, and intangible resources such as R\&D personnel and technical resources. Technical management capability refers to the ability of enterprises to operate and update resources used in $R \& D$ activities such as optimizing equipment utilization and matching equipment and resources [47].

Technical mechanisms facilitate the storage of technical resources, improve the utilization efficiency of technical resources, promote innovative technology advantages and the transformation of innovative technology into achievements, and ultimately induce enterprises to successfully develop innovative products [48]. The technical mechanism helps companies coordinate, integrate, and apply existing knowledge resources, enabling them to introduce new products and services to the market rapidly and gain innovative advantages [36]. R\&D input intensity and $R \& D$ team size have a significant positive impact on innovation performance, accelerating technology introduction, which helps improve innovation efficiency, the strength of technical innovation, and innovation performance [49]. While increasing enterprises' R\&D investment, it is also necessary to strengthen the incentives for the management of $R \& D$ personnel, improve the corporate governance mechanism, and maximize the role of $R \& D$ investment.

\subsection{OIC User Behavior Module}

Users are a crucial component of OICs and a major knowledge source of innovation. The effective operation of an OIC requires full utilization of knowledge resources, and also depends on whether external users can continuously provide more knowledge resources. Therefore, it is necessary to study community user behavior. User behavior in the online community mainly covers innovation and interaction behaviors. User innovation behavior refers to the behaviors of users actively posting 
creative ideas. User interaction behavior refers to the ways users interact such as through viewing, commenting, praising, and voting for specific issues [50].

\subsubsection{User Innovation Behavior}

User innovation behavior is manifested in users proposing innovative ideas to satisfy their intrinsic motivation such as acquiring knowledge, and extrinsic motivation such as recognition by others. In an OIC, users share their knowledge by posting ideas, which contain important knowledge resources for corporate innovation [51]. The most important innovations of enterprises are a result of the users' creative ideas, thus, the active participation of users in open innovation is an important knowledge source for enterprises [52].

\subsubsection{User Interaction Behavior}

In OICs, user interaction behavior can be classified into two types: interaction within users, and the interaction between users and the enterprise.

Interaction with peers in the community can help users understand the advantages and disadvantages of existing ideas, and thus improve the quality of ideas and, in turn, the knowledge base. Feedback has a significant effect on the users' innovation contribution. The more feedback users receive, the more they tend to contribute ideas [53,54]. Moreover, users have an impact on the feedback provision activity, in that those who receive more attention will continue to contribute high-quality ideas for a long time [4]. User interactions can encourage other users to innovate, contribute more ideas, and help companies use collective knowledge to reduce uncertainty in decision making $[55,56]$.

User-to-business interaction can help companies assess the quality and creative value of existing ideas. Ideas with a larger number of comments and votes are often more in line with the market's needs as well as the users' individual needs. Thus, some misunderstandings or prejudices can be overcome through collective knowledge. Full utilization of innovation resources helps increase product satisfaction and user loyalty. Active user interaction is the key to the success of an OIC, helping to maintain the stability, sustainability, and effectiveness of the community [2].

\section{Data Collection and Processing}

\subsection{The Xiaomi OIC}

The Xiaomi Corporation is a Chinese electronics company founded in 2010 and headquartered in Beijing. Xiaomi makes and invests in smartphones, mobile apps, laptops, bags, trimmers, earphones, MI Television, shoes, fitness bands, and many other products. In June 2018, Xiaomi issued the Millet Group Public Offering Depositary Receipt and Prospectus, which mentioned that there are a large number of active users in the Xiaomi OIC, and that these users actively advise the enterprise on product development.

In terms of patent protection, as of 31 December 2018, Xiaomi had successfully applied for 7753 patents. Xiaomi has also signed a patent cross-licensing agreement or technology purchase agreement with the top tech companies such as Microsoft, Qualcomm, and Nokia for rapid upgrading of patented technology.

In terms of R\&D investment, since its establishment, Xiaomi has always attached great importance to technology investment and talent development. It has attracted many outstanding technical personnel through multiple means and established a leading personnel organization in the fields of intelligent hardware R\&D, artificial intelligence, and data analysis. As of March 2018, the number of R\&D personnel in Xiaomi was 5515, accounting for almost $40 \%$ of its total employees. The R\&D team mainly comprised front-end engineers, algorithm engineers, operation and maintenance engineers, software test engineers, and R\&D personnel. 
Xiaomi fully utilizes its OIC to collect market information and user feedback, interact with users to understand their needs, integrate users into the product design process, determine the direction of innovation development, and create open-source product development models. At present, Xiaomi is leading in the aspects of patent protection, R\&D investment, and management.

This study selected the Xiaomi OIC as the research object for the following reasons.

(1) Feasibility of obtaining enterprise innovation performance data

As of December 2018, Xiaomi has successfully applied for 7753 patents, all of which are public, so it is feasible to use the number of patents as the enterprise innovation performance.

(2) Feasibility of data acquisition in the OIC

The Xiaomi OIC has a huge amount of posted content, user comments, and other interactive data as well as the number of product releases by the community, which can be obtained using a web spider.

(3) Number of users

As of December 2018, the Xiaomi OIC had more than 50 million registered users, and over 10,000 users were active daily. The numbers of users and posts have been stable and consistently growing. Valuable feedback on products continues to help Xiaomi achieve product innovation.

\subsection{Data Collection}

This article used the Python spider to obtain data from the Xiaomi OIC (http://www.miui.com/forum. php?forumlist=1). Since the OIC has dozens of functionally different sub-communities, we selected the New Feature Suggestion sub-community and the Product Release sub-community based on the conceptual model in Figure 1. The New Feature Suggestion sub-community contains creative ideas from users including suggestions for the innovation and improvement of Xiaomi products. The Product Release sub-community contains details about the upcoming release of Xiaomi's innovative products.

The Xiaomi OIC stores only 1000 pages of data, which probably covers the last eight months. We collected data from September 1, 2017 to December 31, 2018, resulting in 1276 data points from the Product Release sub-community, and 38,615 data points from the New Feature Suggestion sub-community.

Using the Rainpat Patent Search System (http://www.rainpat.com/Home/Index), we obtained the Xiaomi patent information to measure the enterprise's innovation performance. The Rainpat Patent Search System contains patent data for 99 countries and regions and covers more than 95 million patents. Taking into account the time lag of innovation performance from the aspect of patents, this study collected 7753 patent data points from Xiaomi, spanning June 8, 2016 to December 31, 2018. These data include patent name, application date, publication date, and patent type.

\subsection{Data Cleaning and Descriptive Statistics}

We employed the following three steps for data cleansing: (1) Harmonization of time formats: The time format of posts made in the OIC in the last seven days is depicted as "N days ago", and thus, the timing of posts is converted into a "year/month/day" format; (2) posts without contents are deleted; and (3) there is often a lag between patent application and publication. For some patents, this lag far exceeds the average due to macro policy adjustment and other uncontrollable external factors. Therefore, to maximize data integrity and control for the outlier bias, the delay date was processed with shrinkage. The descriptive statistics for each data item after cleaning are given in Table 1 . The average delay date, which refers to the gap between the patent application date and its publication day, is 160 days, or about five months. 
Table 1. Descriptive statistics summary.

\begin{tabular}{|c|c|c|c|c|c|}
\hline Item & Measures & Average & Min & Max & Std.Dev \\
\hline \multirow{2}{*}{$\begin{array}{c}\text { Patent } \\
\text { information }\end{array}$} & Monthly patent applications & 235 & 146 & 325 & 47 \\
\hline & Average wait time & 160 & 48 & 270 & 52 \\
\hline \multirow{4}{*}{$\begin{array}{c}\text { New Feature } \\
\text { Suggestion } \\
\text { sub-community }\end{array}$} & Monthly number of users & 2140 & 1248 & 3126 & 528 \\
\hline & Monthly number of posts & 2737 & 1513 & 4266 & 725 \\
\hline & Monthly number of comments & 17,083 & 8040 & 35,050 & 6543 \\
\hline & Monthly number of views & $30,324,058$ & 942,642 & $405,535,223$ & $104,065,196$ \\
\hline $\begin{array}{l}\text { Product Release } \\
\text { sub-community }\end{array}$ & $\begin{array}{c}\text { Monthly number of product } \\
\text { releases }\end{array}$ & 28 & 4 & 104 & 26 \\
\hline
\end{tabular}

\section{Establishment and Simulation of a System Dynamics Model}

First, the system boundaries and basic assumptions were determined to conduct a causal analysis of the system, and a system dynamics model for innovation performance was constructed. Then, based on the objective data from the Xiaomi OIC and Prospectus, the parameters of the system dynamics model were assigned values and simulated. Finally, based on the simulation analysis, results and discussions are proposed to explore the impact mechanism of OICs on enterprise innovation performance.

\subsection{System Analysis}

\subsubsection{Modeling Purposes}

The system dynamics model of the impact of innovation performance was proposed for the following purposes.

(1) Determining causality. We analyzed three subsystems that affect innovation performance by identifying the logical relationship and feedback mechanism of various factors within the subsystem, determining the causal relationships between factors, and illustrating the relationships.

(2) Defining the quantitative relationship between variables. According to the system dynamics modeling method, the qualitative relationships between variables were further examined to obtain the quantitative relationships between the variables, and thus, stock flow graphs were constructed.

(3) System development trend analysis. Combining the objective data from the Xiaomi OIC with the model parameters and through simulation analysis, we determined the degree of impact of various factors on innovation performance and the change in innovation performance, to provide suggestions for OIC development.

\subsubsection{System Boundary Determination}

System dynamics simulates the operation of real-world systems by modeling; thus, the boundaries of the system need to be clearly defined before modeling is initiated. According to the conceptual model in Figure 1, the open innovation system is divided into knowledge management, user behavior, and governance mechanism subsystems. The knowledge management subsystem is determined by the internal influencing factors of knowledge recognition, knowledge acquisition, knowledge transformation and knowledge application, which help the enterprise transform users' knowledge resources into its innovation performance. The user behavior subsystem is determined by the internal influencing factors of user innovation and interaction behavior, which results in the creation of knowledge resources. The governance mechanism subsystem is determined by the internal influencing factors of organizational and technical mechanisms, which promote the knowledge management ability of the enterprise. 


\subsubsection{Basic Assumptions}

System dynamics is based on conditional prediction, emphasizing basic assumptions in estimating results. The basic assumptions of this study are as follows.

Assumption 1: The system input is the OIC user, who provides knowledge resources through online posts, and the output is the enterprise innovation performance, measured mainly by the number of patents.

Assumption 2: User interaction behaviors such as viewing and commenting are conducive to improving creative ideas, and thus help employees access and evaluate ideas. Consequently, the greater the number of views and comments, the higher the quality of creative ideas.

Assumption 3: Unpredictable factors inside and outside the enterprise such as the transfer of employee are not considered.

\subsection{Causal Relationship Analysis}

\subsubsection{Causal Relationship of Knowledge Management Subsystem}

In the knowledge recognition process, companies assess the quality of existing ideas, ignoring those that have no innovative value for the enterprise and focusing on identifying high-quality innovative ideas. In the knowledge acquisition process, enterprises evaluate the feasibility of implementing existing ideas and obtain knowledge resources from external users to transform them into internal knowledge resources [39]. Therefore, the knowledge recognition and knowledge acquisition abilities have a positive impact on the idea adoption and conversion rates in the user behavior subsystem.

In the knowledge transformation process, the high-quality and feasible ideas selected through the knowledge recognition and acquisition processes are transformed into innovative products; thus, the knowledge transformation ability has a positive impact on the idea conversion rate in the user behavior subsystem.

In the knowledge application process, the enterprise's R\&D investment and management expense in the knowledge management subsystem determine the utilization of innovative product resources, and protect innovative technologies involved in innovative product development by applying for patents. The literature indicates that technology introduction, R\&D personnel, and R\&D investment will have a positive impact on the knowledge recognition, knowledge acquisition, and knowledge transformation abilities [57].

In summary, the main influencing factors of the knowledge management subsystem are technology introduction, R\&D personnel, and R\&D investment. These factors jointly determine the behavioral changes and system structure of the knowledge management subsystem, as shown in Figure 2. The intensity of technology introduction and number of R\&D personnel positively affect knowledge recognition, acquisition, and conversion abilities; all three abilities as well as knowledge application ability, are positively affected by R\&D investment in the governance subsystem. 


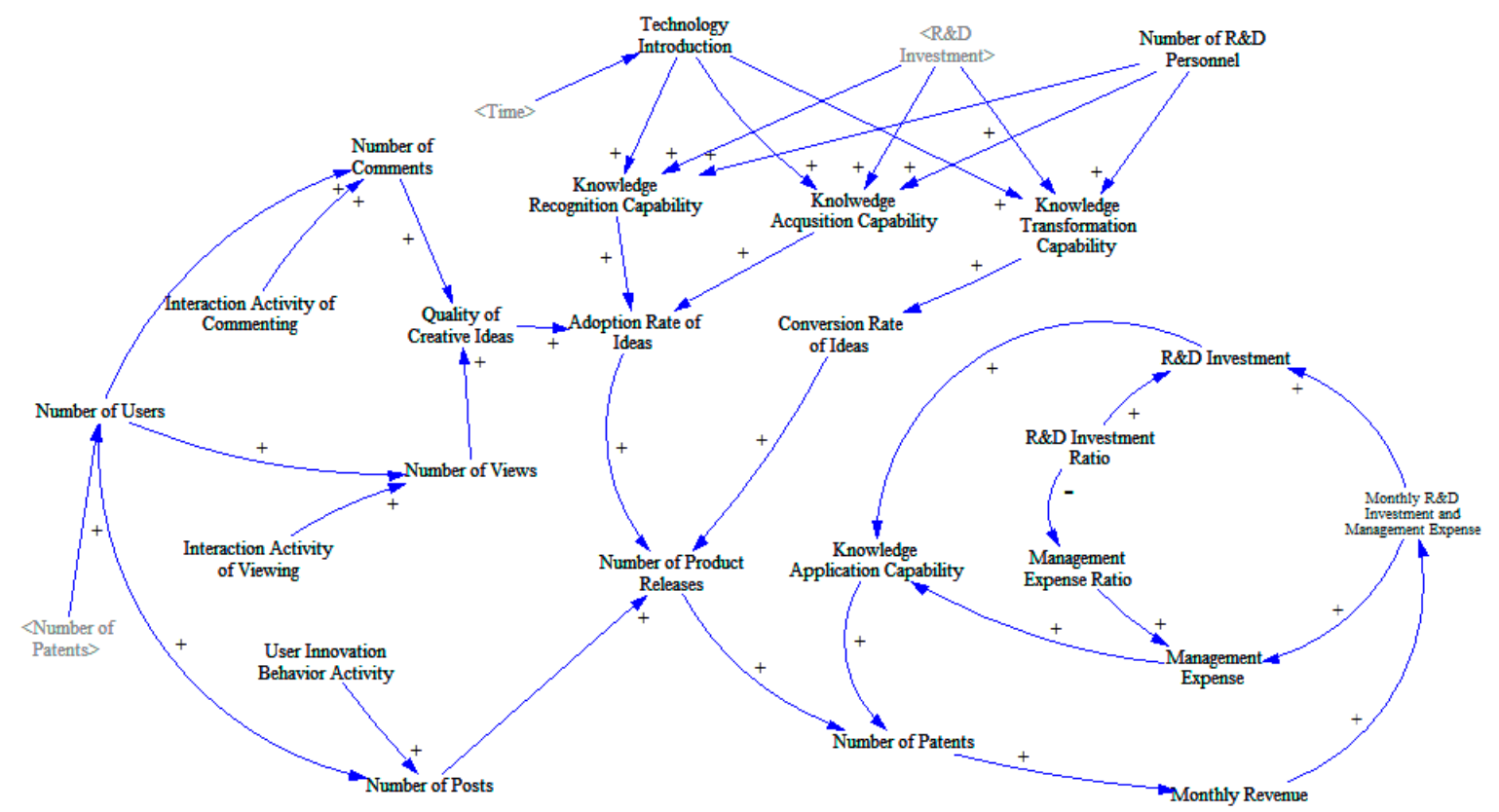

Figure 2. General causal relationship diagram.

\subsubsection{Causal Relationship of Governance Mechanism Subsystem}

By investing a large amount of R\&D and management, enterprises can ensure normal operation of the technical and organizational mechanisms, improve the application ability of knowledge resources, and ultimately help transform knowledge resources into innovation performance, which is reflected by the number of patents [39]. The innovation performance of an enterprise has a positive impact on its organizational and technical mechanisms by influencing financial resources [58]. Through the commercial transformation of open innovation performance, enterprises will introduce new services or new products to the market, which not only satisfy the requirements of users and enhance the reputation of the enterprise, but also bring about an increase in revenue [33]. Part of the revenue will be invested in $R \& D$ and management, thus increasing the total R\&D investment and management expense. If the total $R \& D$ investment and management expense is to remain unchanged, the proportion of $R \& D$ investment should be increased, and accordingly, the proportion of management expense will drop.

In summary, the main influencing factors of the governance mechanism subsystem are the number of patents, monthly revenue, total $R \& D$ and management expense, $R \& D$ investment ratio, and management expense ratio. These influencing factors jointly determine the behavioral changes and system structure of the OIC's governance mechanism subsystem, as shown in Figure 2. R\&D investment positively affects the number of patents through the knowledge application capability in the knowledge management subsystem; the number of patents positively affects total $R \& D$ and management expense through revenues; the total $R \& D$ and management expense has a positive impact on the $R \& D$ and management expense ratios; and the proportion of $R \& D$ investment has a negative impact on the proportion of management expense.

\subsubsection{Causal Relationship of User Behavior Subsystem}

In an increasingly competitive global environment, companies relax boundaries, gain access to external knowledge resources through OICs, and transform them into internal knowledge resources, which is of critical importance for companies to gain a competitive advantage. In an OIC, users are the center of the innovation process. User groups usually include individuals with the intention of providing different levels of contributions [59], which increases the possibility of the market success of innovation [56]. The literature states that the continuous contribution of creative ideas by users has a positive impact on innovation performance, which, in turn, affects user behavior [60]. 
In the Xiaomi OIC, users convey their innovative ideas by posting, viewing, and commenting. Therefore, the number of posts in the community over a period of time is related not only to the number of users, but also to the enthusiasm behind the users' posting behavior, that is, the innovation enthusiasm of the user. Similarly, the number of views and comments in the community over a period of time is related not only to the number of users, but also to the enthusiasm behind the users' viewing and commenting behavior, that is, the interaction enthusiasm of the user.

Research shows that, in the Starbuck OIC, only one of the 500 user-submitted ideas was chosen for implementation, and whether an idea can be implemented depends largely on the degree of attention that the idea generates [61]. Therefore, interaction behavior helps improve the ideas in posts and reduce the uncertainty in decision making by facilitating better understanding [60]. Posts receiving high attention include more users demanding information and having higher innovative quality; thus, they are more easily adopted by enterprises.

In summary, the user behavior subsystem mainly includes the number of users, interaction enthusiasm behavior reflected in comments and views, users' innovation enthusiasm behavior, number of posts, number of views, number of comments, quality of creative ideas, adoption rate of ideas, and number of product releases. Together, these influencing factors determine the behavioral changes and system structure of the OIC's user behavior subsystem, as shown in Figure 2. The number of community users has a positive impact on the number of posts, views, and comments; the numbers of views and comments have a positive impact on the quality of creative ideas; the quality of creative ideas positively affects the number of product releases through the idea adoption rate; and the creative ideas in the posts are eventually transformed into products. Thus, the adoption rate of ideas, the conversion rate of ideas, and number of posts positively affect the number of product releases [62].

\subsubsection{Causality Diagram}

The causal relationship diagrams of the three OIC subsystems were integrated to obtain the general causal relationship diagram for the entire OIC, as shown in Figure 2. The model comprises eight positive feedback loops, and one negative feedback loop.

\subsection{System Dynamics Modeling}

On the basis of the general causal diagram in Figure 2, the system stock flow diagram was drawn using the Vensim PLE software, and is shown in Figure 3.

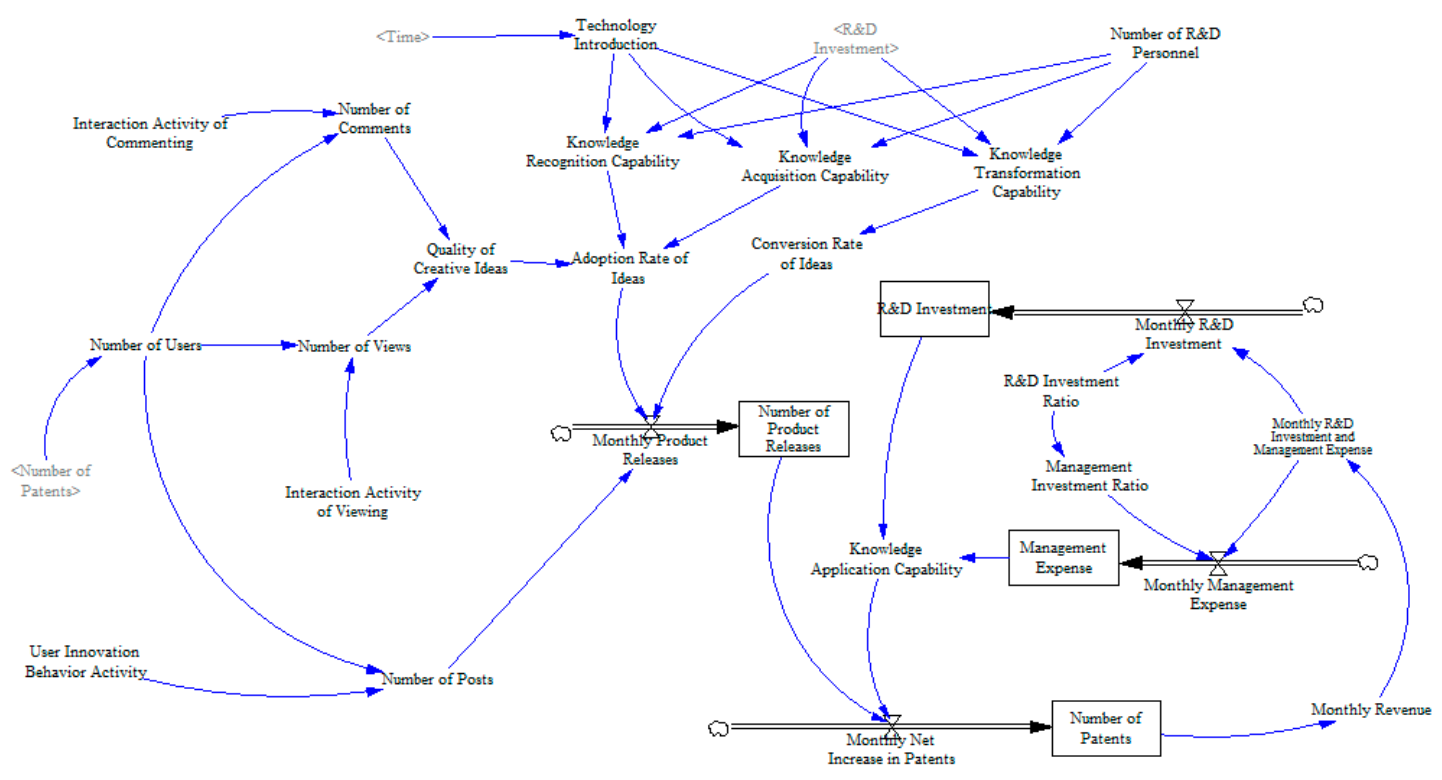

Figure 3. System stock flow diagram. 
Variables and Calculations

(1) State Variables

As can be seen from Table 1 , the average wait time of patents was 160 days. Considering that the patent, a measure of innovation performance, has a five-month time lag, the OIC data spanned from September 1, 2017 to December 31, 2018, and the patent information spanned from February 1, 2018 to December 31, 2018. As of August 31, 2017, the cumulative number of products released by Xiaomi's OIC was 874 , and as of January 31, 2018, the cumulative number of patents published by Xiaomi was 5173.

The statistics given in the Xiaomi Prospectus on R\&D investment and management expense are shown in Table 2. Xiaomi's R\&D investment and management expense in 2017 was 3.151 billion yuan and 4.4 billion yuan, respectively. Therefore, from January 2017 to August 2017, R\&D investment was about 2.1 billion yuan and management expense was about 2.9 billion yuan; taking into account $R \& D$ investment and management expense in 2015 and 2016, the initial values of R\&D investment and management expense were set to 60 billion yuan and 85 billion yuan, respectively.

Table 2. Xiaomi's R\&D investment and management expense.

\begin{tabular}{cccc}
\hline Items & $\mathbf{2 0 1 7}$ & $\mathbf{2 0 1 6}$ & $\mathbf{2 0 1 5}$ \\
\hline R\&D investment (billion yuan) & 31.51 & 21.04 & 15.12 \\
R\&D investment/annual revenue & $2.75 \%$ & $3.07 \%$ & $2.26 \%$ \\
Management expense (billion yuan) & 44 & 29.89 & 22 \\
Management expense/annual revenue & $3.80 \%$ & $4.37 \%$ & $3.36 \%$ \\
Annual revenue (billion yuan) & 1146 & 684 & 668 \\
\hline
\end{tabular}

Following Equations (1)-(4), state variables have cumulative values over time.

$$
\begin{gathered}
\text { Number of product releases = INTEG (Monthly product releases, 874) } \\
\text { R\&D investment = INTEG (Monthly R\&D investment, 60) } \\
\text { Management expense = INTEG (Monthly management expense, 85) } \\
\text { Number of patents = INTEG (Monthly net increase in patents, 5173) }
\end{gathered}
$$

\section{(2) Constant Variables}

According to Table 1, during September 2017-December 2018, the average monthly number of users was 2140 , of posts was 2737 , of comments was 17,083 , and of views was $30,324,058$. Therefore, auxiliary variables in the user behavior subsystem can be calulated as shown in Equations (5)-(7).

Interaction activity of viewing $=$ Monthly number of views/Monthly number of users $=14,170$

Interaction activity of commenting $=$ Monthly number of comments/Monthly number of users $=7.98$

User Innovation behavior activity $=$ Monthly number of posts/Monthly number of users $=1.28$

According to Xiaomi's 2018 Prospectus, the number of R\&D personnel was 5515. From Table 2, on average, Xiaomi invested about $7 \%$ of its annual revenue in R\&D investment and management expense: $3 \%$ in $R \& D$ investment and $4 \%$ in management expense. Therefore, the R\&D investment ratio was $3 / 7$ and the management expense ratio was $4 / 7$. 
(3) Auxiliary Variables

The positive impact coefficients of technology introduction, R\&D investment, and R\&D personnel on knowledge recognition ability, knowledge acquisition ability, and knowledge transformation ability were $1,0.75$, and 0.45 , respectively [63]. Therefore, auxiliary variables in the knowledge management subsystem can be calculated as follows.

Knowledge recognition capability $=$ Number of $R \& D$ personnel $\times$ Technology introduction $\times$ R\&D investment $/ 10,000$

Knowledge acquisition capability $=0.75 \times$ Number of R\&D personnel $\times$ Technology introduction $\times$ R\&D investment $/ 10,000$

Knowledge transformation capability $=0.45 \times$ Number of R\&D personnel $\times$ Technology introduction $\times R \& D$ investment $/ 10,000$

The Function Suggestion sub-community provides users suggestions for the innovation and improvement of Xiaomi's product function. Therefore, auxiliary variables in the user behavior subsystem can be calculated as shown in Equations (11)-(16).

Number of views $=$ Number of users $\times$ Interaction activity of viewing

Number of comments $=$ Number of users $\times$ Interaction activity of commenting

Number of posts $=$ Number of users $\times$ User innovation behavior activity

Quality of creative ideas $=($ Number of comments + Number of views $/ 10,000) / 1000$

Adoption rate of ideas $=($ Creative idea quality $\times$ Knowledge recognition ability $\times$ Knowledge acquisition ability)/10,000

Conversion rate of ideas $=$ Knowledge transformation ability $/ 10,000$

(4) Rate Variables

Patents have a five-month time lag. Therefore, rate variables in the governance mechanism subsystem can be calculated as shown in Equations (17)-(20).

Monthly investment in R\&D and management $=$ Monthly revenue $\times 0.07$

Monthly R\&D investment $=$ Monthly revenue $\times 0.07 \times 3 / 7$

Monthly management expense $=$ Monthly revenue $\times 0.07 \times 4 / 7$

Monthly net increase in patents $=$ DELAYFIXED (Number of product releases

$\times$ Knowledge application ability/100, 5, 0)

In summary, the start time of the model simulation was September 1, 2017, the end time was December 31, 2018, and the time step was one month; all model parameters were set as shown in Table 3. In addition to the above variables, other variables were calculated based on the behavioral changes and system structure of the Xiaomi OIC. 
Table 3. Model parameters.

\begin{tabular}{|c|c|c|c|}
\hline No & Variable & Type & Equation \\
\hline 1 & Number of product releases & \multirow{4}{*}{ State } & INTEG (Monthly product releases, 874) \\
\hline 2 & Number of patents & & INTEG (Monthly net increase in patents, 5173) \\
\hline 3 & R\&D investment & & INTEG (Monthly R\&D investment, 60) \\
\hline 4 & Management expense & & INTEG (Monthly management expense, 85) \\
\hline 5 & Technology introduction & Exogenous & WITH LOOKUP(Time) \\
\hline 6 & Interaction activity of viewing & \multirow{9}{*}{ Constant } & 14,170 \\
\hline 7 & Interaction activity of commenting & & 7.98 \\
\hline 8 & User innovation behavior activity & & 1.28 \\
\hline 9 & Number of R\&D personnel & & 5515 \\
\hline 10 & $\begin{array}{l}\mathrm{R} \& \mathrm{D} \text { and management expense } \\
\text { ratio }\end{array}$ & & 0.07 \\
\hline 11 & R\&D investment ratio & & $0.07 \times 3 / 7$ \\
\hline 12 & FINAL TIME & & 16 \\
\hline 13 & INITIAL TIME & & 1 \\
\hline 14 & TIME STEP & & 1 \\
\hline 15 & Knowledge recognition capability & \multirow{18}{*}{ Auxiliary } & $\begin{array}{l}\text { Number of R\&D personnel } \times \text { Technology } \\
\text { introduction } \times \text { R\&D investment } / 1 \times 10^{`} 5\end{array}$ \\
\hline 16 & Knowledge acquisition capability & & $\begin{array}{l}0.75 \times \text { Number of R\&D personnel } \times \text { Technology } \\
\text { introduction } \times \text { R\&D investment } / 1 \times 10^{\wedge} 5\end{array}$ \\
\hline 17 & $\begin{array}{l}\text { Knowledge transformation } \\
\text { capability }\end{array}$ & & $\begin{array}{l}0.45 \times \text { Number of R\&D personnel } \times \text { Technology } \\
\text { introduction } \times \text { R\&D investment } / 1 \times 10^{\wedge} 5\end{array}$ \\
\hline 18 & Knowledge application capability & & $\begin{array}{c}0.29 \times(R \& D \text { investment }+ \text { Management } \\
\text { expense })\end{array}$ \\
\hline 19 & Number of users & & Number of Patents $\times 0.25$ \\
\hline 20 & Number of views & & $\begin{array}{c}\text { Number of users } \times \text { Interaction activity of } \\
\text { viewing }\end{array}$ \\
\hline 21 & Number of comments & & $\begin{array}{c}\text { Number of users* Interaction activity of } \\
\text { commenting }\end{array}$ \\
\hline 22 & Number of posts & & $\begin{array}{c}\text { Number of users } \times \text { User innovation behavior } \\
\text { activity }\end{array}$ \\
\hline 23 & Quality of creative ideas & & $\begin{array}{c}\text { (Number of comments }+ \text { Number of } \\
\left.\text { views } / 1 \times 10^{\wedge} 4\right) / 1 \times 10^{\wedge} 3\end{array}$ \\
\hline 24 & Adoption rate of ideas & & $\begin{array}{c}\text { (Quality of creative ideas } \times \text { Knowledge } \\
\text { recognition ability } \times \text { Knowledge acquisition } \\
\text { ability) } / 1 \times 10^{\wedge} 5\end{array}$ \\
\hline 25 & Conversion rate of ideas & & Knowledge transformation ability/100 \\
\hline 26 & Monthly revenue & & Number of patents $\times 0.016$ \\
\hline 27 & Management expense ratio & & $1-R \& D$ investment ratio \\
\hline 28 & Monthly product releases & & $\begin{array}{l}\text { Adoption rate of ideas } \times \text { Conversion rate of } \\
\text { ideas } \times \text { Number of posts }\end{array}$ \\
\hline 29 & $\begin{array}{l}\text { Monthly R\&D investment and } \\
\text { management expense }\end{array}$ & & Monthly revenue $\times 0.07$ \\
\hline 30 & Monthly R\&D investment & & Monthly revenue $\times 0.07 \times 3 / 7$ \\
\hline 31 & Monthly management expense & & Monthly revenue $\times 0.07 \times 4 / 7$ \\
\hline 32 & Monthly net increase in patents & & $\begin{array}{l}\text { DELAY FIXED (Number of product releases } \times \\
\text { Knowledge application ability } / 100,5 \text { ) }\end{array}$ \\
\hline
\end{tabular}

\subsection{Model Validation}

\subsubsection{A Runs Test}

A runs test is conducted to determine whether the output of the model is different under different simulation steps. Taking the number of patents as an example, we simulated the three steps of Time Step $=0.25$, Time Step $=0.5$, and Time Step $=1$, as shown in Figure 4. During the running of the model, the output results of the three simulation steps were not significantly different, and the system behavior was basically stable; therefore, our model cleared the runs test. 


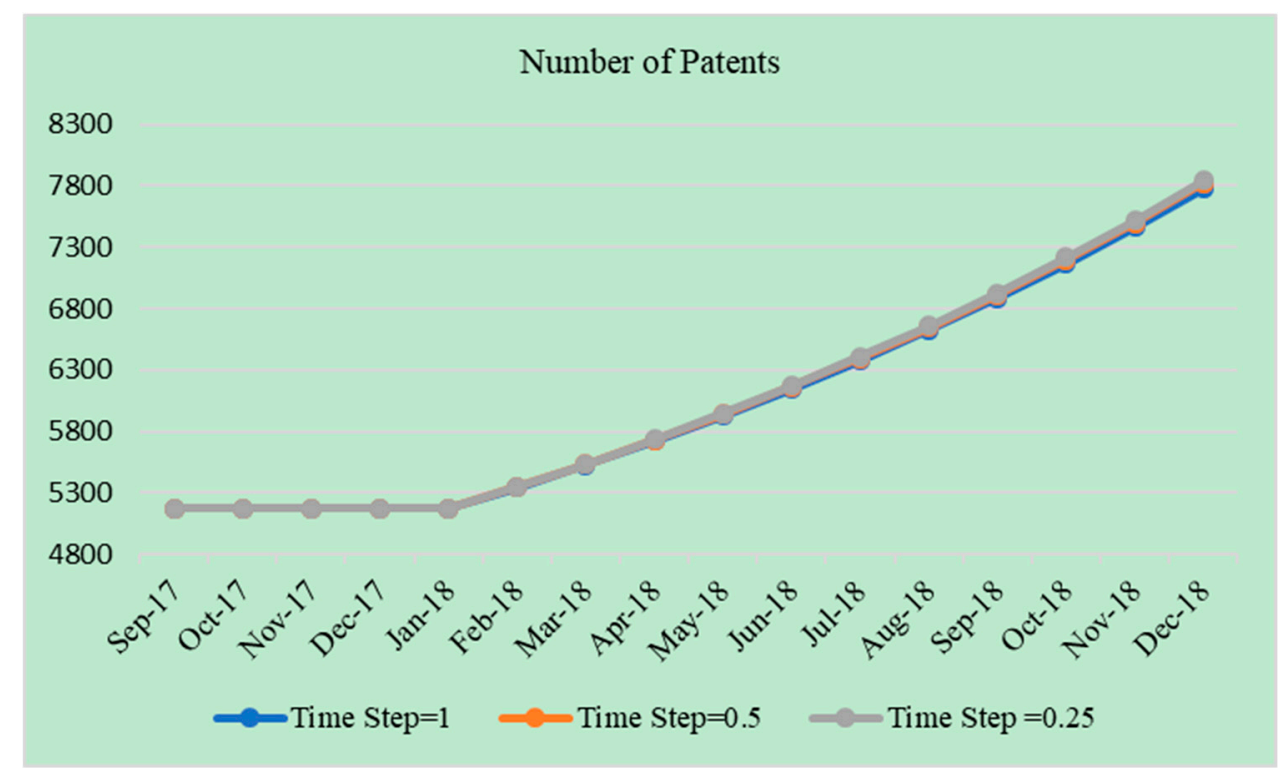

Figure 4. A runs test result.

\subsubsection{Historical Test}

The historical test examines the accuracy of a model based on the relative error value of the actual value and the predicted value. In this study, the two important parameters: number of patents and number of product releases, were historically tested, as shown in Tables 4 and 5 . The relative error between the predicted value of the simulation results and the actual value of the real system was not more than $10 \%$. Since the historical test does not impose strict criteria, if the relative error is less than $15 \%$, the model can be considered to have cleared the test [32]. Thus, our model matched the standard of the true data and passed the historical test.

Table 4. Number of patents: historical test results.

\begin{tabular}{ccccc}
\hline Month & Actual Value & Predicted Value & Difference & Error \\
\hline Feb 2018 & 5412 & 5344.09 & 67.91 & $1.25 \%$ \\
Mar 2018 & 5658 & 5526.39 & 131.61 & $2.33 \%$ \\
Apr 2018 & 5870 & 5720.46 & 149.54 & $2.55 \%$ \\
May 2018 & 6137 & 5926.82 & 210.18 & $3.42 \%$ \\
Jun 2018 & 6390 & 6146.03 & 243.97 & $3.82 \%$ \\
Jul 2018 & 6536 & 6378.61 & 157.39 & $2.41 \%$ \\
Aug 2018 & 6788 & 6625.05 & 162.95 & $2.40 \%$ \\
Sep 2018 & 6992 & 6886.54 & 105.46 & $1.51 \%$ \\
Oct 2018 & 7167 & 7164.40 & 2.60 & $0.04 \%$ \\
Nov 2018 & 7501 & 7460.06 & 40.94 & $0.55 \%$ \\
Dec 2018 & 7753 & 7774.76 & -21.76 & $-0.28 \%$ \\
\hline
\end{tabular}


Table 5. Number of Product Releases: Historical Test Results.

\begin{tabular}{ccccc}
\hline Month & Actual Value & Predicted Value & Difference & Error \\
\hline Sep 2017 & 921 & 895.09 & 25.91 & $2.81 \%$ \\
Oct 2017 & 944 & 917.17 & 26.83 & $2.84 \%$ \\
Nov 2017 & 953 & 940.12 & 12.88 & $1.35 \%$ \\
Dec 2017 & 963 & 963.84 & -0.84 & $-0.09 \%$ \\
Jan 2018 & 979 & 988.18 & -9.18 & $-0.94 \%$ \\
Feb 2018 & 986 & 1013.02 & -27.02 & $-2.74 \%$ \\
Mar 2018 & 992 & 1039.91 & -47.91 & $-4.83 \%$ \\
Apr 2018 & 1000 & 1069.00 & -69 & $-6.90 \%$ \\
May 2018 & 1004 & 1100.44 & -96.44 & $-9.61 \%$ \\
Jun 2018 & 1053 & 1133.02 & -80.02 & $-7.60 \%$ \\
Jul 2018 & 1094 & 1166.63 & -72.63 & $-6.64 \%$ \\
Aug 2018 & 1129 & 1201.12 & -72.12 & $-6.39 \%$ \\
Sep 2018 & 1168 & 1236.31 & -68.31 & $-5.85 \%$ \\
Oct 2018 & 1272 & 1271.96 & 0.04 & $0.00 \%$ \\
\hline
\end{tabular}

\subsubsection{Sensitivity Test}

The sensitivity test is used to determine the sensitivity of the model to changes in the value of the constant parameter within a reasonable range. That is, if the model variable does not change drastically in response to a slight change in the constant parameter, it is considered to have cleared the sensitivity test. This study took a constant value of the management expense ratio as an example to analyze the influence of a change of $-3 \%,-1 \%, 1 \%$, and $3 \%$ in the parameter value on the state variable of the number of patents. The sensitivity test results are shown in Figure 5. The number of patents did not change much under different parameter values, thus, our model cleared the sensitivity test.

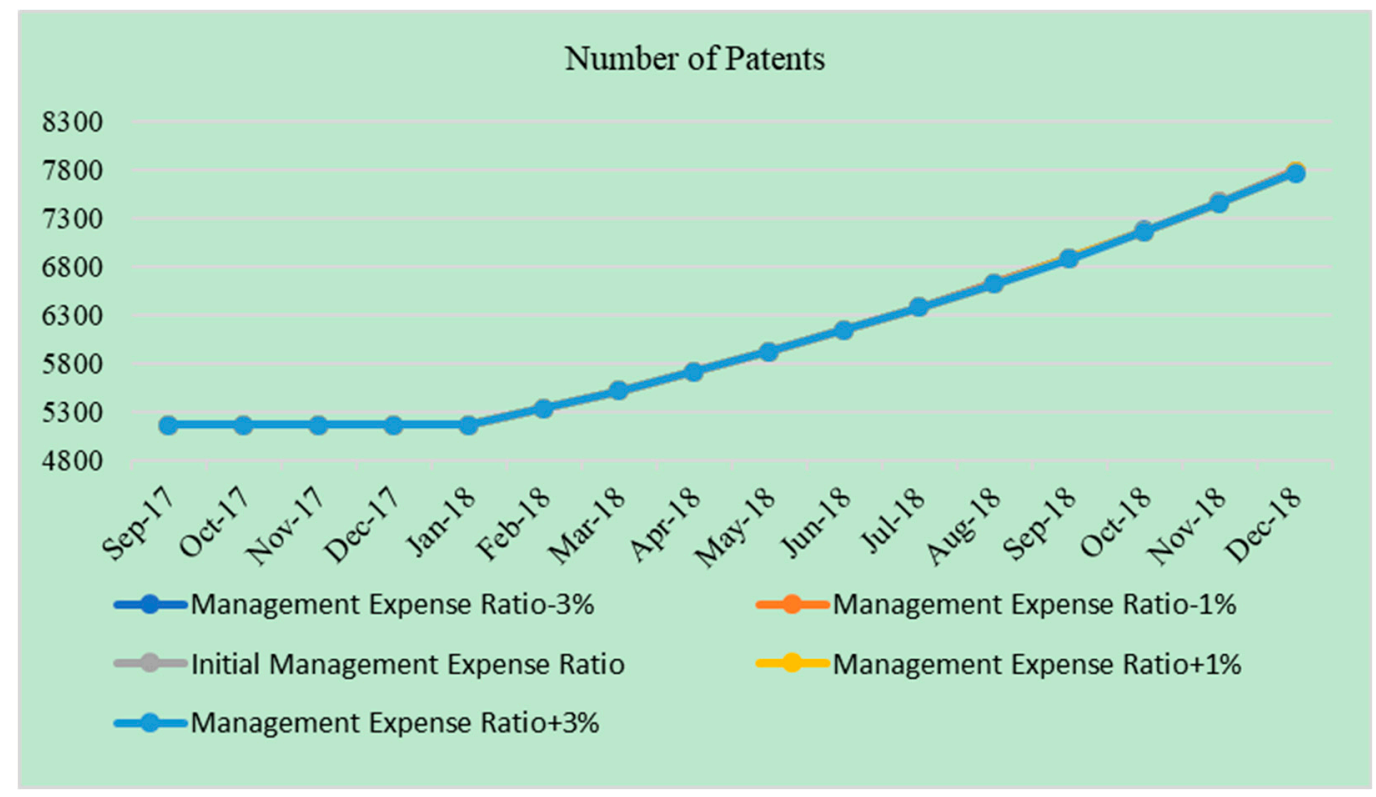

Figure 5. Sensitivity test results.

\subsection{Simulation Analysis}

Our proposed system dynamics model for the Xiaomi OIC cleared the tests above, which means it can accurately describe the enterprise open innovation process of the enterprise. Therefore, the user behavior, governance mechanism, and knowledge management subsystems were simulated and analyzed separately, and the effects of various variables on the system behavior were observed. Based on the analysis results, we proposed strategies for the management and development of OICs. 


\subsubsection{User Behavior Simulation Analysis Results}

According to the causal relationships in the user behavior subsystem, as the dependent variable, the number of products is affected by three independent variables: the number of posts (which represents user innovation behavior) and the number of comments and views, which represent user interaction behavior. Based on its initial value, the development trend of the dependent variable is simulated by increasing the three independent variables by $5 \%, 10 \%$, and $20 \%$. The results are shown in Figures $6-8$. The number of product releases in the OIC has increased over time, and has a positive correlation with the number of posts, comments, and views. The increase in the number of posts has the most significant impact on the number of product releases, followed by that in the number of comments. However, the impact of the number of views on the number of product releases is relatively insignificant.

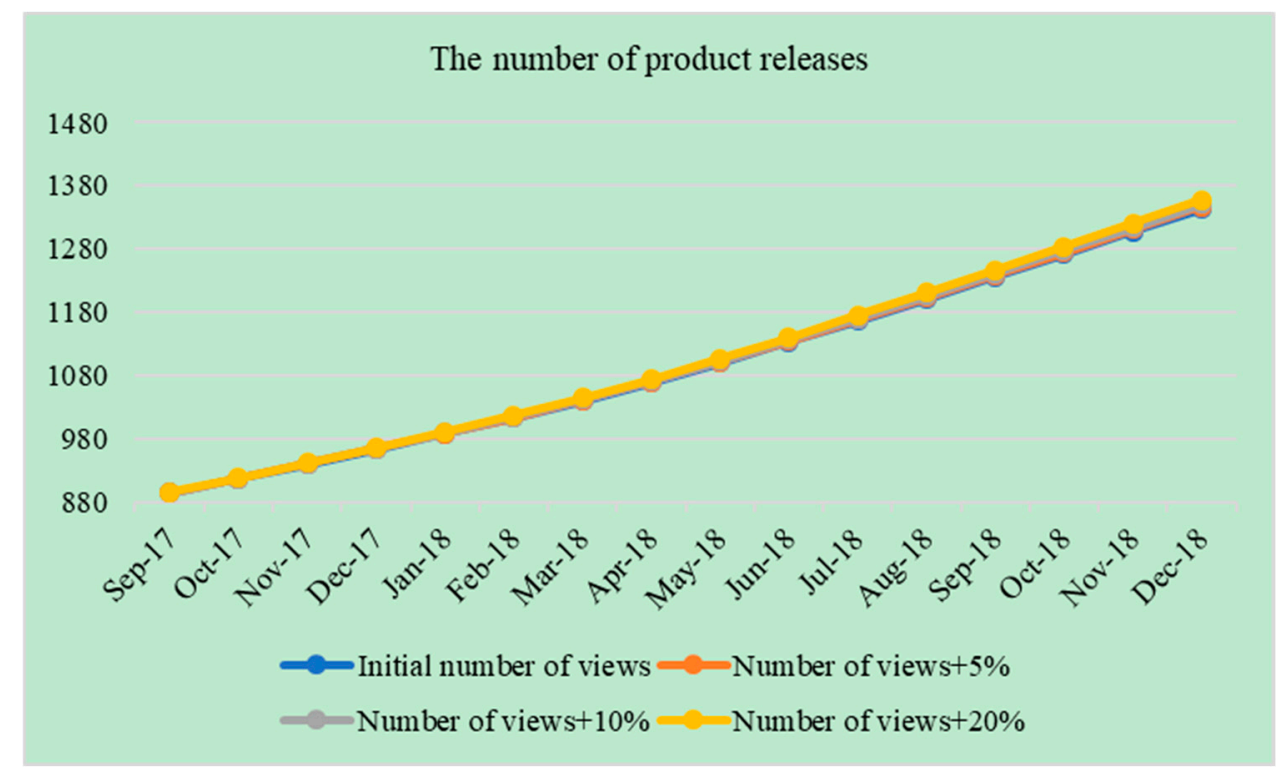

Figure 6. Impact of the number of views on the number of product releases.

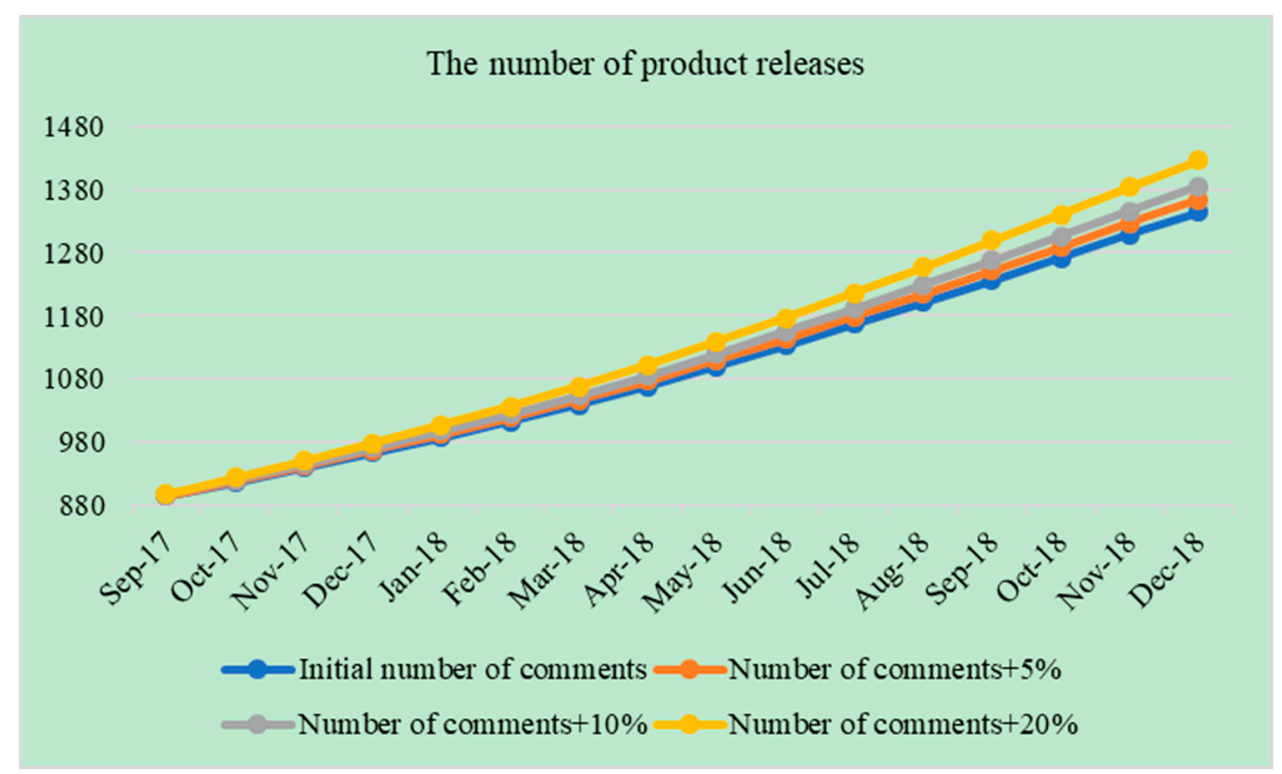

Figure 7. Impact of the number of comments on the number of product releases. 


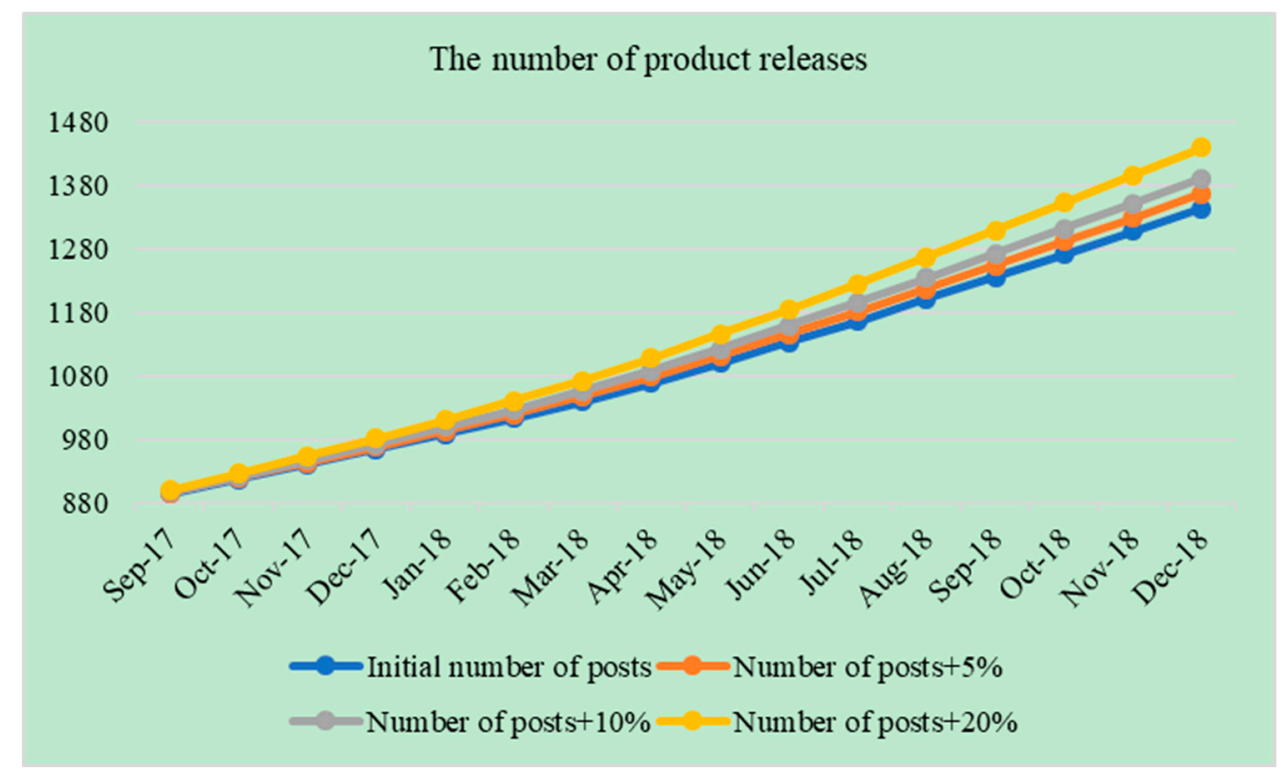

Figure 8. Impact of the number of posts on the number of product releases.

\subsubsection{Governance Mechanism Simulation Analysis Results}

According to the causal relationships in the governance mechanism subsystem, the number of patents is affected by the R\&D investment ratio, and the number of users is affected by the R\&D and management expense. Based on the initial values, the development trends of the two dependent variables, the number of patents, and of users were simulated by increasing the two independent variables by $5 \%, 10 \%$, and $20 \%$. The results are shown in Figures 9 and 10.

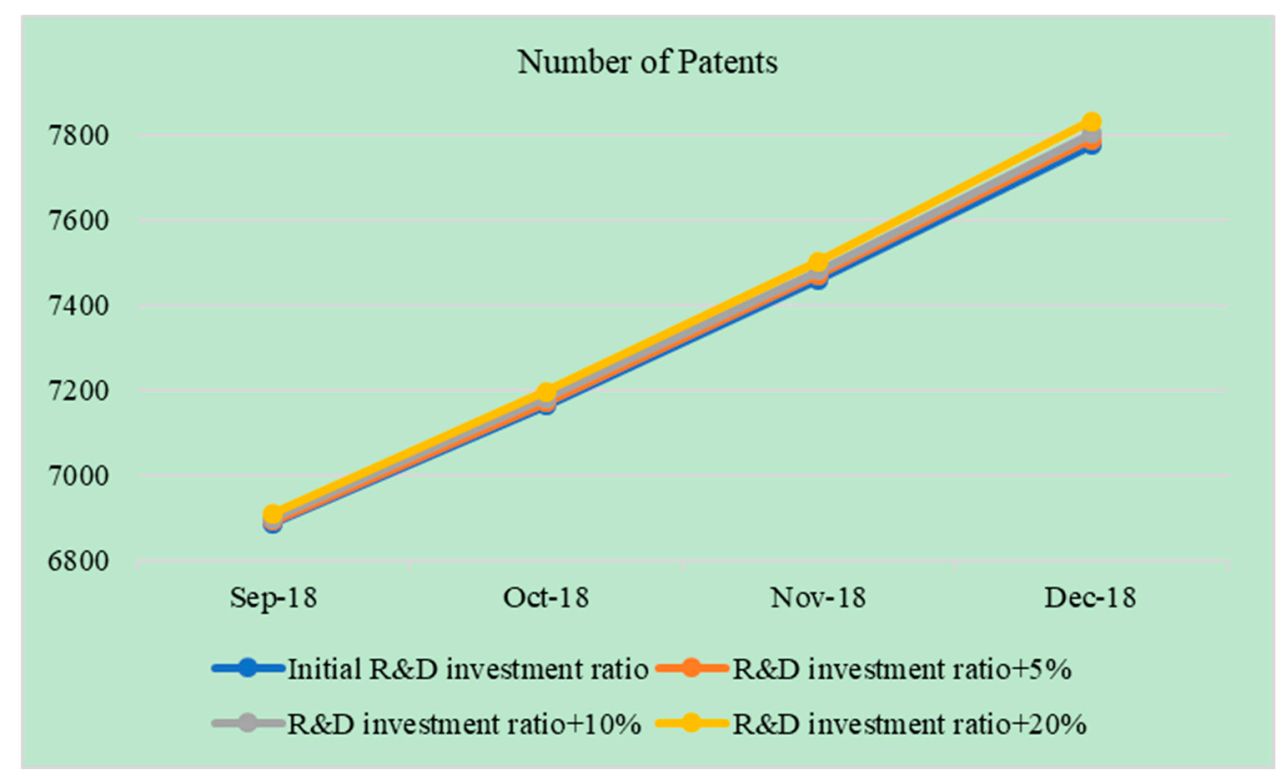

Figure 9. Impact of R\&D investment ratio on the number of patents. 


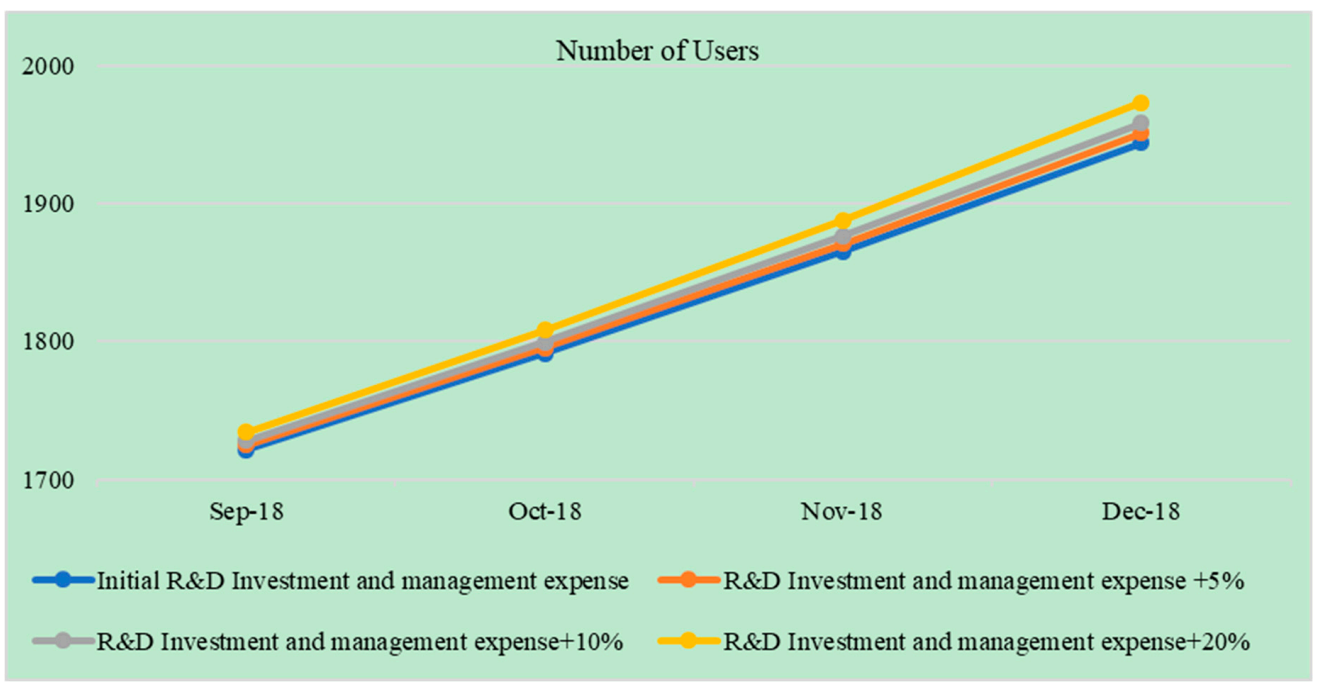

Figure 10. Impact of R\&D investment and management expense on the number of users.

As seen in Figure 9, with an increase in the proportion of R\&D investment per month, the number of patents also increased. Therefore, to a certain extent, the impact of $R \& D$ investment on the number of patents is clearer than that of management expense (as shown in Figure 5).

According to Figure 10, with an increase in R\&D investment and management expense per month, the number of users in the OIC, which is positively correlated with both these variables, also increases. The increase in the number of users also drives the enterprise to enter a new round of feedback loop in the open innovation process, thus ensuring that it can continuously transform the OIC's knowledge resources into its own innovation performance.

\subsubsection{Knowledge Management Simulation Analysis Results}

According to the causal relationships in the knowledge management subsystem, the dependent variable knowledge application capability is affected by the $R \& D$ investment ratio. Based on its initial value, the development trend of knowledge application capability is simulated by increasing R\&D investment ratio by $5 \%, 10 \%$, and $20 \%$. The result is shown in Figure 11 . The R\&D investment has a positive impact on the knowledge application capability. Therefore, enterprises should increase their investment in R\&D, which, in turn, can enhance their ability to identify, acquire, and transform knowledge resources.

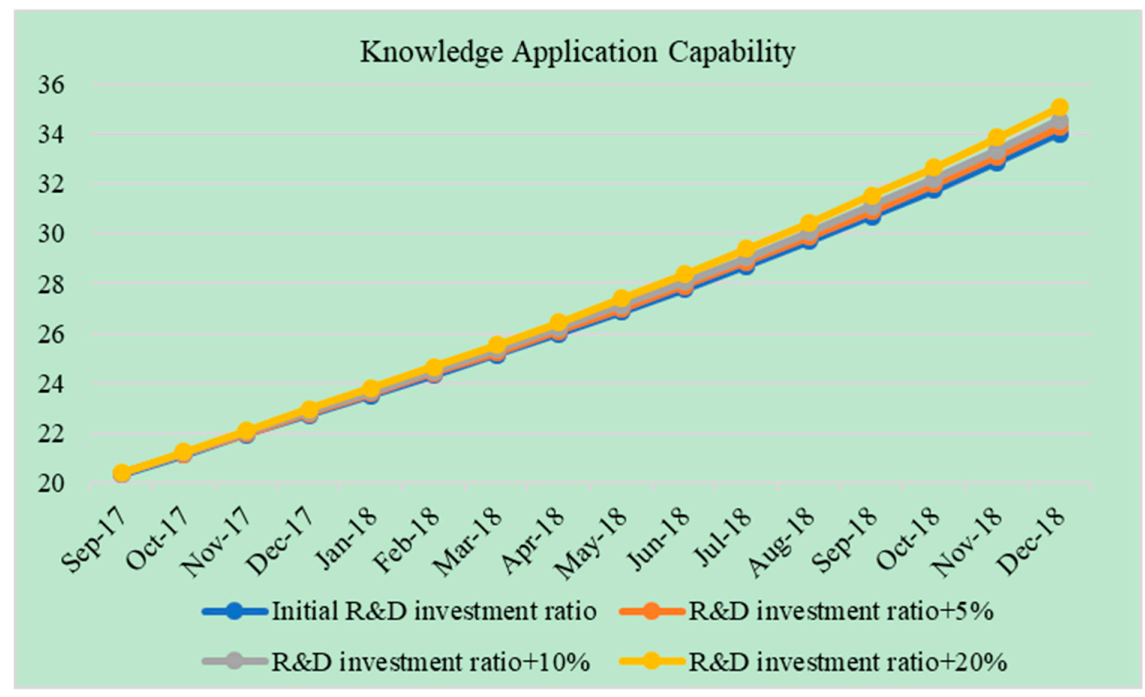

Figure 11. Impact of R\&D investment ratio on knowledge application capability. 


\subsection{Results and Discussions}

First, the number of product releases in the Xiaomi OIC is positively correlated with the number of posts, comments, and views. Compared with user interaction behavior (i.e., commenting and viewing), the impact of user innovation behavior (i.e., posting) on enterprise innovation performance (i.e., number of patents) is clearer. Specifically, regarding interaction behavior, the impact of the users' commenting behavior on innovation performance (i.e., number of product releases) is relatively clearer than that of their viewing behavior. One possible explanation for this effect is that user innovation behavior is the key factor in the open innovation process: it provides a wealth of knowledge resources to help the OIC increase the number of product releases, which is directly related to the enterprise's innovation performance. At the user behavior level, the continuous supply of knowledge in OICs requires users to continually contribute knowledge, which is transformed and applied by the community.

Second, the governance mechanism (i.e., R\&D investment and management expense), which comprises technical and organizational mechanisms, positively affects the innovation performance of enterprises. In turn, innovation performance has a positive impact on the governance mechanism by affecting the scale of enterprises and their financial resources. Compared with the organizational mechanism (i.e., management expense), the impact of the technical mechanism (i.e., R\&D investment) on the innovation performance is clearer. A possible explanation for this result could be that R\&D investment and management expense required for innovation performance directly depend on the adequacy of the financial resources. Innovation performance helps enterprises expand their scale, enhance profitability, and increase the utility of financial resources.

Third, the governance mechanism helps to increase the number of users in the OIC, and, in turn, affects the user innovation and interaction behavior. One possible explanation for this result is that users are willing to take the initiative to propose ideas, driven mainly by their intrinsic motivation as well as the extrinsic motivation of non-material incentives such as a sense of accomplishment, self-identification, and recognition by others. Considering intrinsic motivation, users expect to achieve higher returns and values through product innovation, and thus, enjoy contributing to solving product-related problems. In the process, they also have the opportunity to develop their own capabilities and gain more knowledge. Communities with better innovation performance are more likely to satisfy the aforementioned intrinsic motivations [64]. Considering the user extrinsic motivation, people participate in virtual communities for functional or social benefits such as access to information and knowledge, and to find friends. Users and companies have different pursuits: companies seek to improve their business capabilities and generate higher turnover and benefits; meanwhile, users, in addition to sharing ideas with like-minded enthusiasts, want to identify potential employers outside the community to boost their career development process [59]. Users are eager to gain an esteemed reputation in the eyes of their peers or companies to improve their career prospects [65]. In an OIC, individuals often need to be externally recognized and rewarded. Peer recognition triggers individual motivation, and communities with good innovation performance often provide users with opportunities to win peer recognition [66].

Fourth, the technical mechanism positively affects knowledge application capability, which, in turn, has a positive impact on the innovation performance of enterprises. As a dynamic capability, knowledge management ability helps enterprises to continuously update specific resources and enhance certain capabilities, indirectly affecting their innovation performance by influencing their strategic configuration [67]. The companies' knowledge management capabilities affect their problem-solving mechanism and speed of resolution [68]. Therefore, knowledge management capabilities help companies perceive market changes, collect user and industry information, improve the efficiency of the knowledge value realization process, and achieve technological and product innovation, all of which positively impacts innovation performance [34]. 


\section{Conclusions}

\subsection{Contributions}

\subsubsection{Theoretical Contributions}

The literature has mostly investigated OICs from the perspective of either users or enterprises. This study comprehensively integrated both of these perspectives and introduced the governance mechanism, community user behavior, and knowledge management into the conceptual model. This further enriches and expands the theoretical research on OICs.

Most previous studies have been based on qualitative and empirical research and ignored the interaction of causal relationships and the cumulative effects of time. This study used system dynamics to examine the evolution of open innovation considering the time lag in the open innovation performance.

According to the system dynamics literature in the field of information systems, the assignment of parameter values is based on subjective methods such as consultation with experts. In contrast, this study used a web spider to collect data from the Xiaomi's OIC and other relevant industry reports such as its Prospectus, in an attempt to derive most parameters from real-world systems. As a result, the simulation results were more objective. This offers a new idea for parameter value assignment in system dynamics.

Compared with operational management and project management, the application of system dynamics in information systems is relatively limited. This paper introduces system dynamics into the study of OICs, which enriches the literature.

\subsubsection{Practical Contributions}

In this study, we found that users' posts and comments had significant impacts on product releases. The main goal of the OIC is to capture the users' knowledge resources through the users' posts. The greater the number of creative ideas being contributed to an OIC, the greater the external knowledge resources that can be obtained from the users. Therefore, the enterprise should implement appropriate incentives to promote user innovation enthusiasm and encourage them to actively post in the community, to guide them in the idea contribution process and stimulate the enthusiasm of community members to propose ideas. Simultaneously, the enterprise should promote user interaction enthusiasm for improvement in post quality, which helps the enterprise choose the most innovative and feasible ideas through collective knowledge and indirectly increases the number of product releases in the community.

An improvement in knowledge application ability and high R\&D investment is important for improvement in innovation performance. Specifically, a sound governance mechanism enhances knowledge management capabilities by integrating the knowledge resources of enterprises, and has a positive impact on innovation performance. Enterprise managers should focus on R\&D investment for the establishment of a technical mechanism. In particular, when the R\&D and management budget is limited, the input of technical mechanisms should be further emphasized to promote the continuous transformation of external knowledge resources into innovation performance. According to the feedback loop principle of causality, the enterprise's number of patents will also increase to enhance the knowledge management capabilities.

Enterprises should also focus on the commercial value of innovation performance and work to transform it into business revenue, which will promote the growth of their OICs. This is because communities with better innovation performance also have better governance mechanisms such as strong management and high-quality R\&D personnel, which is helpful in transforming creative ideas into innovative products. Thus, the continuous transformation of knowledge resources in OICs will promote and maintain long-term competitive advantages for enterprises. 


\subsection{Limitations and Future Research}

Since the Xiaomi OIC stores posts only from the last eight months, we used a Python spider to retrieve data from this community from September 2017 to December 2018. In future, more data should be collected for simulation in a broader time span and more in-depth research.

In reality, there are many variables affecting a system. To identify the key influencing factors of the system, the relevant variables selected based on Xiaomi's OIC were relatively limited. For example, in the context of organizational mechanism, this study selected only management expense as a variable, but other variables such as compensation and employee incentives impact the organizational mechanisms. As relationships between real-world system variables are more complicated, subsequent research can explore other variables for specific causality analysis.

Author Contributions: Conceptualization, B.W.; Methodology, B.W.; Software, C.G.; Validation, B.W.; Formal Analysis, B.W.; Investigation, B.W.; Resources, B.W.; Data Curation, C.G.; Writing-Original Draft Preparation, C.G.; Writing-Review \& Editing, B.W.; Visualization, C.G.; Supervision, B.W.; Project Administration, B.W.; Funding Acquisition, B.W.

Funding: This research was funded by [the National Social Science Fund of China "Thirteenth Five-Year Plan" education topic] grant number [BFA180064].

Acknowledgments: We would like to take this opportunity to acknowledge the time and effort devoted by editors and reviewers.

Conflicts of Interest: The authors declare no conflict of interest.

\section{References}

1. Fuller, J.; Hutter, K.; Hautz, J.; Matzler, K. User Roles and Contributions in Innovation-Contest Communities. J. Manag. Inf. Syst. 2014, 31, 273-308. [CrossRef]

2. Schemmann, B.; Herrmann, A.M.; Chappin, M.M.H.; Heimeriks, G.J. Crowdsourcing ideas: Involving ordinary users in the ideation phase of new product development. Res. Policy 2016, 45, 1145-1154. [CrossRef]

3. Liu, M.L.; Hull, C.E.; Hung, Y.T.C. Starting open source collaborative innovation: The antecedents of network formation in community source. Inf. Syst. J. 2017, 27, 643-670. [CrossRef]

4. Huang, Y.; Singh, P.V.; Srinivasan, K. Crowdsourcing New Product Ideas Under Consumer Learning. Manag. Sci. 2014, 60, 2138-2159. [CrossRef]

5. Martinez-Torres, M.R. Analysis of open innovation communities from the perspective of social network analysis. Technol. Anal. Strateg. Manag. 2014, 26, 435-451. [CrossRef]

6. Mahr, D.; Lievens, A. Virtual Lead User Communities: Drivers of Knowledge Creation for Innovation. Res. Policy 2012, 41, 167-177. [CrossRef]

7. Briel, F.V.; Recker, J. Lessons from a failed implementation of an online open innovation community in an innovative organization. Mis Q. Exec. 2017, 16, 35-46.

8. Martinez-Torres, M.R. Application of evolutionary computation techniques for the identification of innovators in open innovation communities. Expert Syst. Appl. 2013, 40, 2503-2510. [CrossRef]

9. Harland, P.E.; Nienaber, A.M. Solving the matchmaking dilemma between companies and external idea contributors. Technol. Anal. Strateg. Manag. 2014, 26, 639-653. [CrossRef]

10. Martínez-Torres, M.R. Content analysis of open innovation communities using latent semantic indexing. Technol. Anal. Strateg. Manag. 2015, 27, 859-875. [CrossRef]

11. Cui, T.R.; Ye, H.; Teo, H.H.; Li, J.Z. Information technology and open innovation. Inf. Manag. 2015, 52, 348-358. [CrossRef]

12. Santoro, G.; Vrontis, D.; Thrassou, A.; Dezi, L. The Internet of Things: Building a knowledge management system for open innovation and knowledge management capacity. Technol. Forecast. Soc. Chang. 2018, 136, 347-354. [CrossRef]

13. Zhou, R.; Qi, G.J. A System Dynamics Model for Open Innovation Community. Int. J. Enterp. Inf. Syst. 2018, 14, 78-88.

14. Shin, K.; Kim, S.J.; Park, G. How does the partner type in R\&D alliances impact technological innovation performance? A study on the Korean biotechnology industry. Asia Pac. J. Manag. 2016, 33, 141-164. 
15. Gold, A.H.; Malhotra, A.; Segars, A.H. Knowledge Management: An Organizational Capabilities Perspective. J. Manag. Inf. Syst. 2001, 18, 185-214. [CrossRef]

16. Chen, L.; Fong, P.S.W. Evaluation of knowledge management performance: An organic approach. Inf. Manag. 2015, 52, 431-453. [CrossRef]

17. Juison, B.; Wardani, S.P.R.; Wibowo, M.A. Innovation Performance of Large Contractor in Indonesia: Influencing Factors and its Impact on Firm's Performance. Procedia Eng. 2017, 171, 370-378. [CrossRef]

18. Palacios-Marques, D.; Roig-Dobon, S.; Comeig, I. Background factors to innovation performance: Results of an empirical study using fsQCA methodology. Qual. Quant. 2016, 51, 1939-1953. [CrossRef]

19. Wang, D.; Nie, R.; Long, R.Y.; Shi, R.Y.; Zhao, Y.Y. Scenario prediction of China's coal production capacity based on system dynamics model. Resour. Conserv. Recycl. 2018, 129, 432-442. [CrossRef]

20. Kunc, M.; Mortenson MJVidgen, R. A computational literature review of the field of System Dynamics from 1974 to 2017. J. Simul. 2018, 12, 115-127. [CrossRef]

21. Tomaskova, H.; Kuhnova, J.; Cimler, R.; Dolezal, O.; Kuca, K. Prediction of population with Alzheimer's disease in the European Union using a system dynamics model. Neuropsychiatr. Dis. Treat. 2016, 12, 1589-1598. [PubMed]

22. Xiao, B.; Chankong, V. A System Dynamics Model for Predicting Supply and Demand of Medical Education Talents in China. Eurasia J. Math. Sci. Technol. Educ. 2017, 13, 5033-5047. [CrossRef]

23. Dasgupta, D.; Debsarkar, A.; Hazra, T.; Bala, B.K.; Gangopadhyay, A.; Chatterjee, D. Scenario of future e-waste generation and recycle-reuse-landfill-based disposal pattern in India: A system dynamics approach [J]. Environ. Dev. Sustain. 2016, 19, 1473-1487. [CrossRef]

24. Pervin, L.; Islam, M.S. System dynamics approach for modeling of sugar beet yield considering the effects of climatic variables. J. Sci. Food Agric. 2015, 95, 515-521. [CrossRef] [PubMed]

25. Hsieh, Y.H.; Chou, Y.H. Modeling the impact of service innovation for small and medium enterprises: A system dynamics approach. Simul. Model. Pract. Theory 2018, 82, 84-102. [CrossRef]

26. Nazareth, D.L.; Choi, J. A system dynamics model for information security management. Inf. Manag. 2015, 52, 123-134. [CrossRef]

27. Faham, E.; Rezvanfar, A.; Mohammadi, S.H.M.; Nohooji, M.R. Using system dynamics to develop education for sustainable development in higher education with the emphasis on the sustainability competencies of students. Technol. Forecast. Soc. Chang. 2016, 123, 307-326. [CrossRef]

28. Jhawar, A.; Garg, S.K. System Dynamics Modelling to Study the Effects of Investment in Information Technology on Logistics Performance: A Case Study from India. IGI Glob. 2016, 5, 19-40. [CrossRef]

29. Ercan, T.; Onat, N.C.; Tatari, O. Investigating carbon footprint reduction potential of public transportation in United States: A system dynamics approach. J. Clean. Prod. 2016, 133, 1260-1276. [CrossRef]

30. Xu, S.H.; Jiang, J.Z. System dynamic simulation of knowledge management based on financial service innovation: A case study of Shanghai FTZ. In Proceedings of the 2017 International Conference on Management Science and Management Innovation, Suzhou, China, 23-25 June 2017; Volume 31, pp. $264-270$.

31. An, L.P.; Du, Y.M.; Tong, L.Y. Study on Return Policy in E-Commerce Environment Based on System Dynamics. In Proceedings of the 2016 Information Technology and Mechatronics Engineering Conference, Chongqing, China, 21-22 May 2016; Volume 24, pp. 428-431.

32. Fang, Y.; Lim, K.H.; Qian, Y.; Feng, B. System Dynamics Modeling for Information Systems Research: Theory of Development and Practical Application. MIS Q. 2018, 42, 1303-1329.

33. Wu, A.H.; Wang, Z.; Chen, S.D. Impact of specific investments, governance mechanisms and behaviors on the performance of cooperative innovation projects. Int. J. Proj. Manag. 2017, 35, 504-515. [CrossRef]

34. Nawab, S.; Nazir, T.; Zahid, M.M.; Fawad, S.M. Knowledge Management, Innovation and Organizational Performance. Int. J. Knowl. Eng. 2015, 1, 43-48. [CrossRef]

35. Ramirez, M.S.; Garcia-Penalvo, F.J. Co-creation and open innovation: Systematic literature review. Comunicar 2018, 54, 9-18. [CrossRef]

36. Srivastava, M.K.; Gnyawali, D.R.; Hatfield, D.E. Behavioral implications of absorptive capacity: The role of technological effort and technological capability in leveraging alliance network technological resources. Technol. Forecast. Soc. Chang. 2015, 92, 346-358. [CrossRef]

37. Bootz, J.P.; Durance, P.; Monti, R. Foresight and knowledge management. New developments in theory and practice. Technol. Forecast. Soc. Chang. 2019, 140, 80-83. [CrossRef] 
38. Guo, R.P.; Cai, L.; Fei, Y.P. Knowledge integration methods, product innovation and high-tech new venture performance in China. Technol. Anal. Strateg. Manag. 2019, 31, 306-318. [CrossRef]

39. Frankort, H.T.W. When does knowledge acquisition in R\&D alliances increase new product development? The moderating roles of technological relatedness and product-market competition [J]. Res. Policy 2016, 45, 291-302.

40. Liang, H.S.; Wei, J.; Wan, X.M. The Change of Enterprise Technological Innovation Capability System and Its Performance Impact Mechanism-New Paradigm of Haier Open Innovation. Manag. Rev. 2018, 30, $281-291$.

41. Tippmann, E.; Scott, P.S.; Parker, A. Boundary Capabilities in MNCs: Knowledge Transformation for Creative Solution Development. J. Manag. Stud. 2017, 54, 455-482. [CrossRef]

42. Taherparvar, N.; Esmaeilpour, R.; Dostar, M. Customer knowledge management, innovation capability and business performance: A case study of the banking industry. J. Knowl. Manag. 2014, 18, 591-610. [CrossRef]

43. Havakhor, T.; Soror, A.A.; Sabherwal, R. Diffusion of knowledge in social media networks: Effects of reputation mechanisms and distribution of knowledge roles. Inf. Syst. J. 2018, 28, 104-141. [CrossRef]

44. Cabrilo, S.; Dahms, S. How strategic knowledge management drives intellectual capital to superior innovation and market performance. J. Knowl. Manag. 2018, 22, 621-648. [CrossRef]

45. Noh, M.; Kim, H.; Jang, H. Learning performance and business performance of knowledge management organizations: The moderating effect of technological capability. Inf. Dev. 2016, 32, 637-654. [CrossRef]

46. Hedstrom, P.; Wennberg, K. Causal mechanisms in organization and innovation studies. Innov. Manag. Policy Pract. 2017, 19, 91-102. [CrossRef]

47. Argote, L.; Hora, M. Organizational Learning and Management of Technology [J]. Prod. Oper. Manag. 2017, 26, 579-590. [CrossRef]

48. Cetindamar, D.; Phaal, R.; Probert, D.R. Technology management as a profession and the challenges ahead. J. Eng. Technol. Manag. 2016, 41,1-13. [CrossRef]

49. Bustinza, O.F.; Gomes, E.; Vendrell-Herrero, F.; Baines, T. Product-service innovation and performance: The role of collaborative partnerships and R\&D intensity. RD Manag. 2019, 49, 33-45.

50. Manniche, J.; Testa, S. Towards a multi-levelled social process perspective on firm innovation: Integrating micro, meso and macro concepts of knowledge creation. Ind. Innov. 2019, 25, 365-388. [CrossRef]

51. Li, M.G.; Kankanhalli, A.; Kim, S.H. Which ideas are more likely to be implemented in online user innovation communities? An empirical analysis. Decis. Support Syst. 2016, 84, 28-40. [CrossRef]

52. Lin, H.W.; Chen, Y.P.; Yang, Y.S. Cluster Analysis of Automobile Innovative Users Based on Interactive Innovation Value. Math. Probl. Eng. 2018. [CrossRef]

53. Qin, M.; Qiao, H.; Chen, L.H. Online User Contribution Behavior in Enterprise-hosted Open Innovation Communities Based on Complex Adaptive System: An Example of Chinese Famous Enterprise-hosted Community. Manag. Rev. 2015, 27, 126-137.

54. Lu, P.; Yuan, S.M.; Wu, J.L. The interaction effect between intra-organizational and inter-organizational control on the project performance of new product development in open innovation. Int. J. Proj. Manag. 2017, 35, 1627-1638. [CrossRef]

55. Graf, J.; Erba, J.; Harn, R.W. The Role of Civility and Anonymity on Perceptions of Online Comments. Mass Commun. Soc. 2017, 20, 526-549. [CrossRef]

56. Kaiserfeld, T. Revolutionizing Innovation: Users, Communities, and Open Innovation. Technol. Cult. 2017, 58, 613-614. [CrossRef]

57. Calof, J.; Meissner, D.; Razheva, A. Overcoming open innovation challenges: A contribution from foresight and foresight networks. Technol. Anal. Strateg. Manag. 2018, 30, 718-733. [CrossRef]

58. Yang, H.J.; Yang, J.J. The effects of transformational leadership, competitive intensity and technological innovation on performance. Technol. Anal. Strateg. Manag. 2019, 31, 292-305. [CrossRef]

59. Parmentier, G.; Mangematin, V. Orchestrating innovation with user communities in the creative industries. Technol. Forecast. Soc. Chang. 2014, 83, 40-53. [CrossRef]

60. Yang, X.M.; Song, S.Q.; Zhao, X.S.; Yu, S.Q. Understanding user behavioral patterns in open knowledge communities. Interact. Learn. Environ. 2018, 26, 245-255. [CrossRef]

61. Hossain, M.; Islam, K.M.Z. Generating Ideas on Online Platforms: A Case Study of "My Starbucks Idea". Arab Econ. Bus. J. 2015, 10, 102-111. [CrossRef]

62. Shin, K.; Kim, E.; Jeong, E. Structural Relationship and Influence between Open Innovation Capacities and Performances. Sustainability 2018, 10, 2787. [CrossRef] 
63. Li, Y.Y. Research on User Contribution and Innovation Management of Enterprise Open Innovation Community-Based on Starbucks Data Analysis [D]. Ph.D. Thesis, Shandong University, Shandong, China, 2017.

64. Li, M.W.; Jia, S.L.; Du, W.Y. Fans as a source of extended innovation capabilities: A case study of Xiaomi Technology. Int. J. Inf. Manag. 2019, 44, 204-208. [CrossRef]

65. Qin, M.; Liang, S. Study on User Recognition Mechanism and Contribution Behavior in Online Innovation Communities: Based on Prosocial Behavior Theory. Nankai Bus. Rev. 2017, 20, 28-39.

66. Yilmaz, F. Social Presence and Transactional Distance as an Antecedent to Knowledge Sharing in Virtual Learning Communities. J. Educ. Comput. Res. 2017, 55, 844-864. [CrossRef]

67. Durmus-Ozdemir, E.; Abdukhoshimov, K. Exploring the mediating role of innovation in the effect of the knowledge management process on performance. Technol. Anal. Strateg. Manag. 2018, 30, 596-608. [CrossRef]

68. Magnier-Watanabe, R.; Benton, C. Management innovation and firm performance: The mediating effects of tacit and explicit knowledge. Knowl. Manag. Res. Pract. 2017, 15, 325-335. [CrossRef]

(C) 2019 by the authors. Licensee MDPI, Basel, Switzerland. This article is an open access article distributed under the terms and conditions of the Creative Commons Attribution (CC BY) license (http://creativecommons.org/licenses/by/4.0/). 